$$
\begin{aligned}
& \text { دراسة مختبرية لحماية سفح المؤخر للهدارات الركامية } \\
& \text { باستخدام السلال الصخرية } \\
& \text { غنية عبد المجيد حياوي }
\end{aligned}
$$

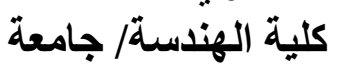

$$
\begin{aligned}
& \text { بهز اد محمد علي نوري } \\
& \text { كلية الهندسة/ جامعة دهوت نوري }
\end{aligned}
$$

\title{
الخلاصة
}

تم في هذا البحث در اسـة مدى ثباتبـة واستقر ار سفح المؤخر للهـدار ات الركاميـة المعرضـة للجريـان

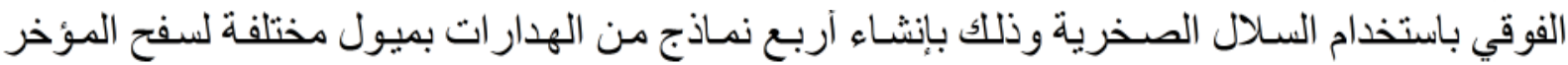
[ 1 V:2.5H,1 V:3H,1 V:4H,1 V:5H]

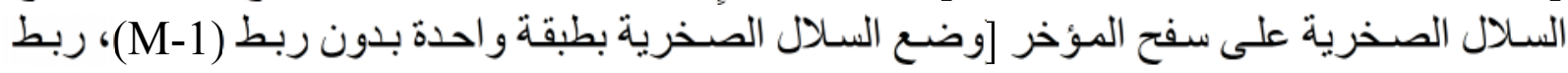
السلال الصخرية أفقيا (M-H)، ربط السلال الصخرية رأسيا (M-V)، وضع وضع السلال الصخرية بطبقتين

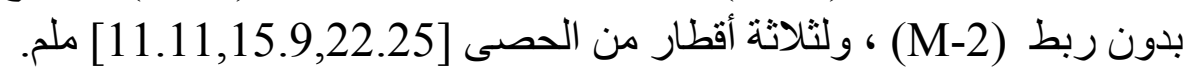

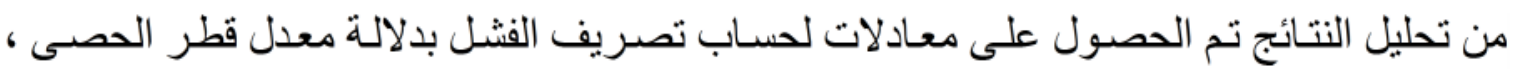

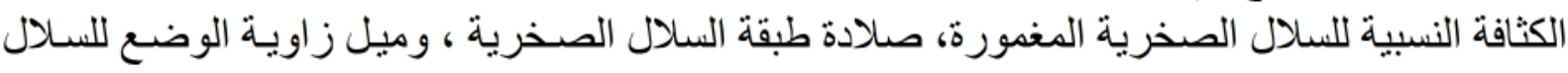

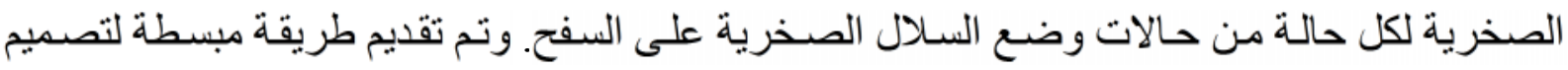

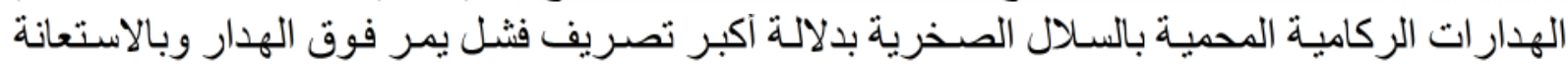
بمنحنيات تصميمية لكل حالة. كما تم اشتقاق نموذج رياضباتي يعتمد على خو اص النمـوذج الفيزيائي

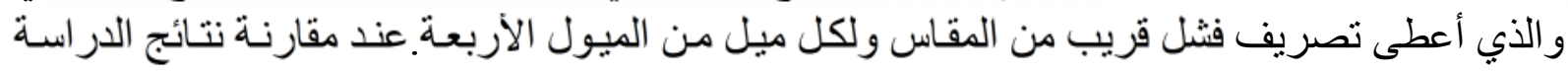

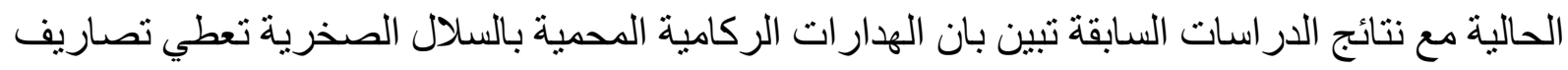

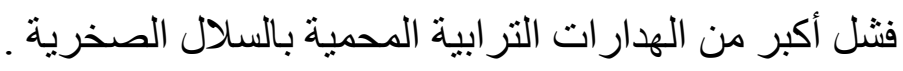

$$
\text { الكلمات الالة:-السلال الصخرية، الهدار ات الركامية }
$$

\section{Laboratory Study Of Protecting Downstream Slope Of Rockfill Weirs Using Gabions}

\author{
Bahzad Mohammad Ali Noori
}

\section{Ghania Abed Al-Majeed Hayawi}

\begin{abstract}
In the present research, the stability of rockfill weirs protected by gabions and subjected to overtopping flow rates under the effect of high flow rates has been studied experimentally. Four weir models with different downstream slopes $[1 \mathrm{~V}: 2.5 \mathrm{H}, 1 \mathrm{~V}: 3 \mathrm{H}, 1 \mathrm{~V}: 4 \mathrm{H}, 1 \mathrm{~V}: 5 \mathrm{H}]$ were constructed and tested. Fourty eight experiments were conducted for four cases of gabions laying on the downstream
\end{abstract}


slope[ laying gabions with one layer and no connections (M-1),laying gabions with lateral connections $(\mathrm{M}-\mathrm{H})$, laying gabions with longitudinal connections (M-V), laying gabions with two layers(M-2] using three gravel diameters $(11.11,15.9$ and 22.25$) \mathrm{mm}$. From the data analysis, many equations were obtained for the estimation of failure unit discharge in terms of equivalent gravel diameter, relative submerged intensity of gabions, gabions layer solidity, and tangent of internal friction angle of gabions, for each case of gabions laying. A simple method was presented for the design of rockfill weirs protected by gabions in terms of maximum failure discharge with the help of design charts obtained from the present study.

A mathematical model depending on the characteristics of the physical model was derived for each slope giving failure unit discharge values that agree quite well with the experimental values.

Comparing results of the present study with those of other investigations shows that rockfill weirs protected by gabions stand higher failure unit discharge than earth weirs protected by gabions.

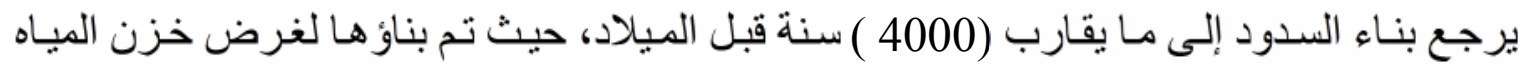

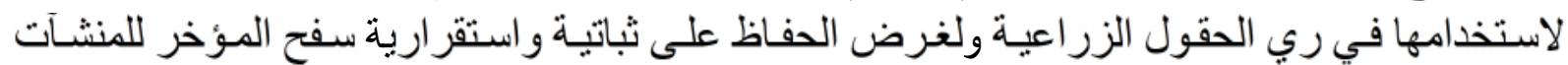

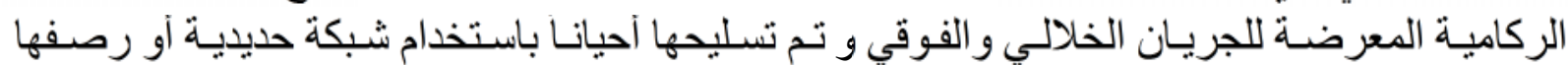
بالصخور الكبيرة أو تغطيتها بالسـالال الصخرية (Gabions) التي تتميز باحتفاظها بنفس نفاذية الكية المواد

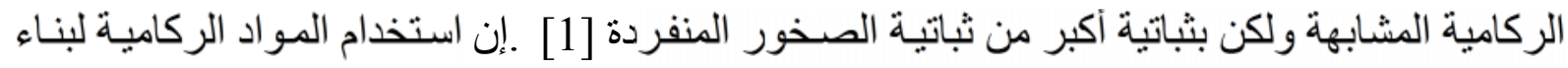

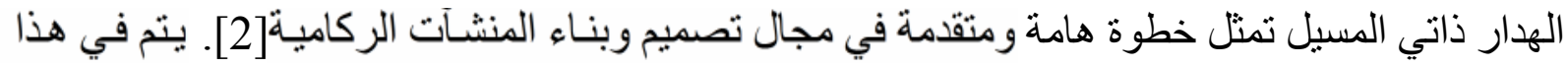

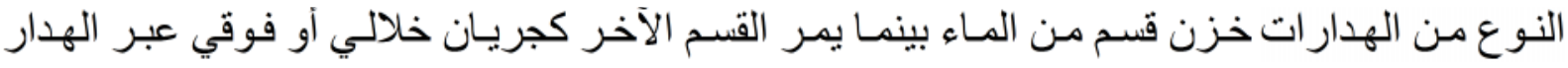

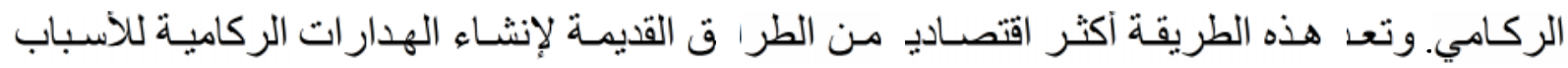

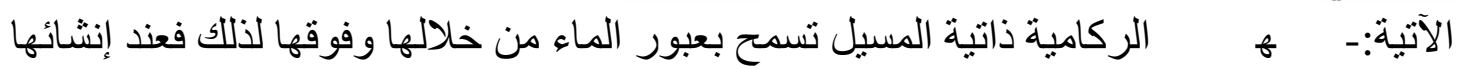


العهار

لتصميم وبناء مسيل مائي تقليدي نظر آ لتبديد طاقة الماء وتهدئتها أثناء مروره

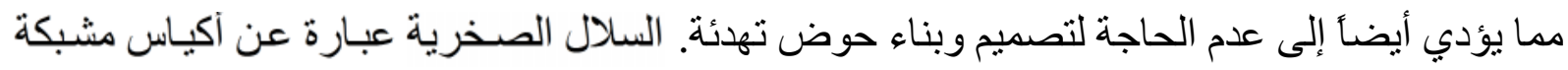

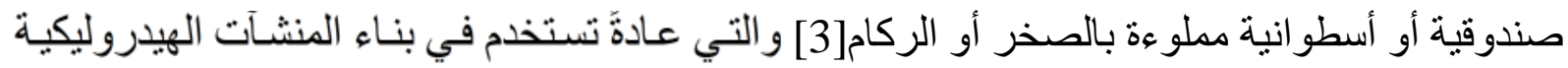
مثل السدود و الأسنان الصخرية لتهذيب الأنهار وكمبددات للطاقة وبناء الجدران الساندة وكذللك في حماية

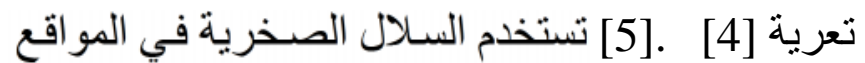

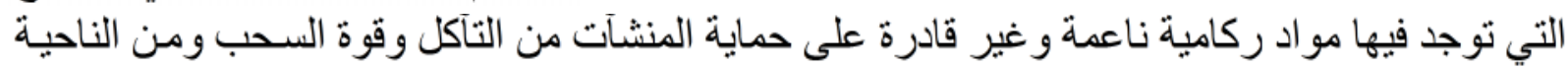
الاقتصادية عند عدم توفر المواد الصخرية ذات الأحجام الكبيرة أي تكون كلفة نقلها من مناطق بعيدة أكثر بالتكسية الحجرية

لال الصخرية و عادةً السلال الصخرية تحتاج إلى (3/1)

.[6] (Riprap)

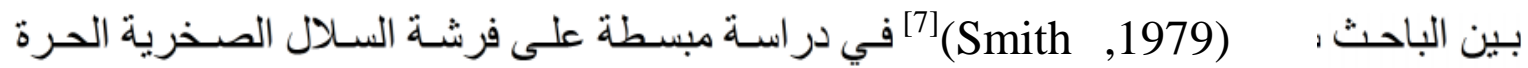
هدار ات تر ابية وبميل لسفح المؤخر (1V:10H) آنها تفشل بسر عة حيث ترتفع حافتها العليا بفعل التبار

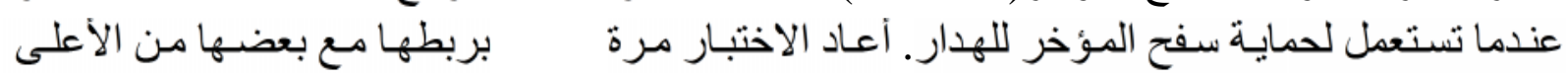

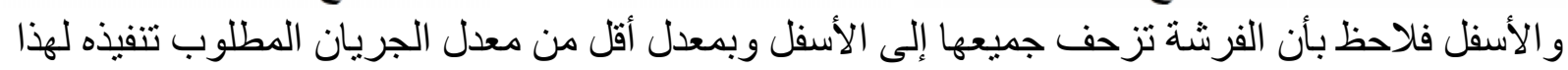
هو لحصول على أقل كلفة محتملة لمادة الحماية للهد

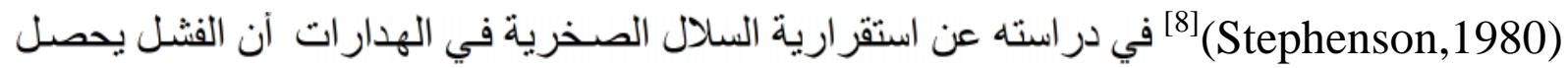

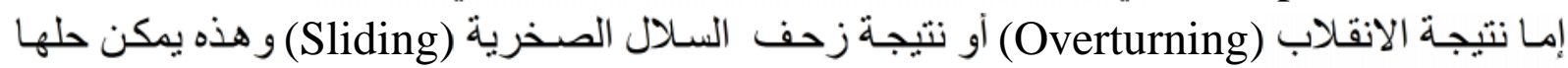
رياضياً حيث وجد علاقة لكل حالة من حالات الفشا للسد الوقتي الصخري في المحطة الكهرومائية في هندور اس من الناحية الهيدروليكية و الذي تـم

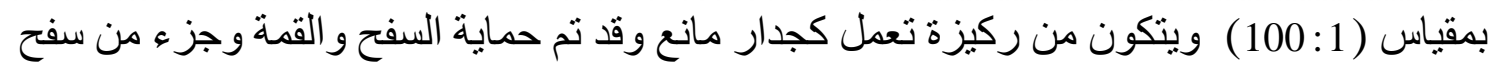

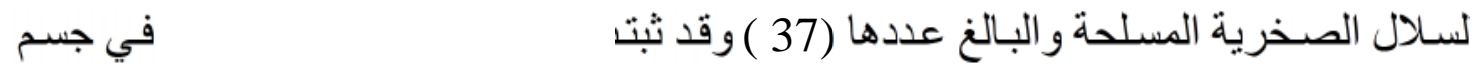

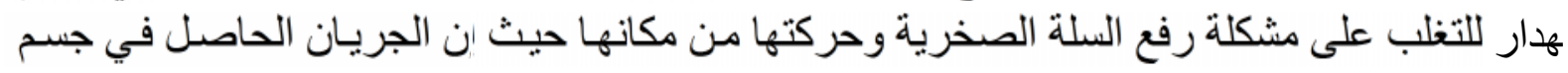
هدار يسبب حدوث تسرب قوي يعمل على دفع السلة الصخرية إلى الأعلى وهذا مـا يسبب في تقليل

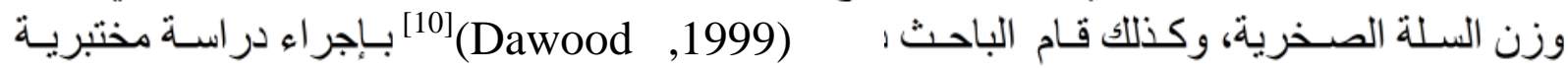

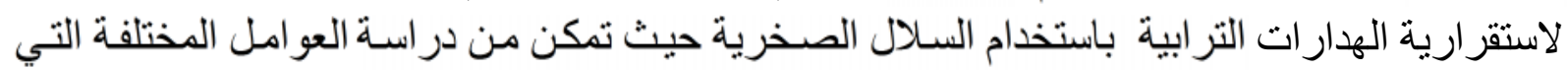

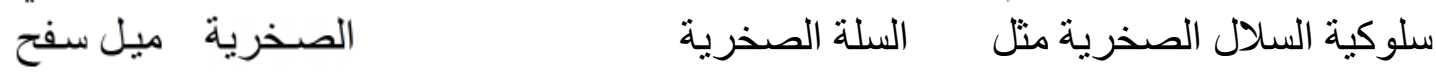

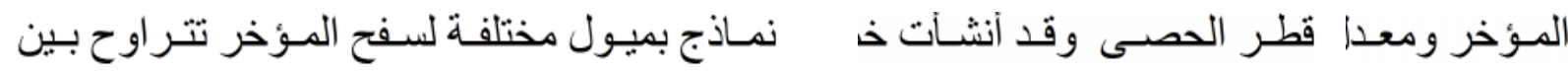
.( $1 \mathrm{~V}: 3 \mathrm{H}) \quad(1 \mathrm{~V}: 10 \mathrm{H})$

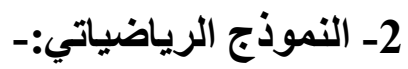

ألرياضياتي يمكن م الفرضبات الآتية:- طبقة الحمابـة تتكون من

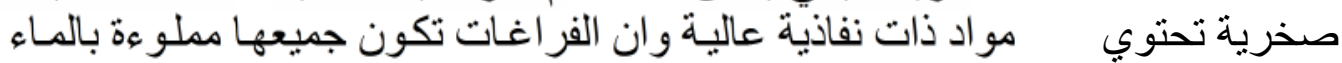

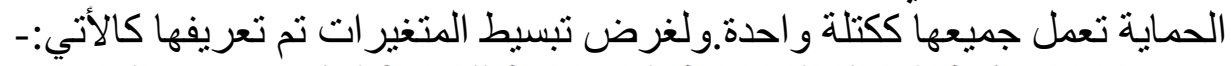

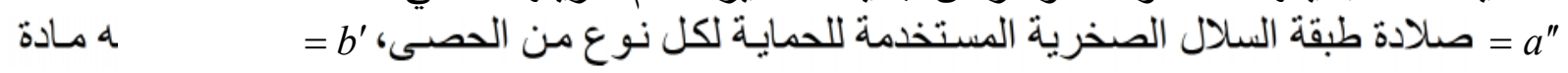

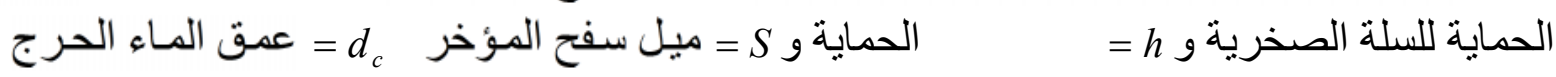




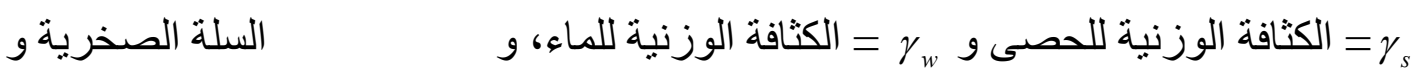

(a" $\left.\left(\frac{\gamma_{s}}{\gamma_{w}}-1\right)=A\right)$

قسمين القسم الأول يتعلق بالعمق الطبيعي للماء و القسم الثاني يتعلق بالقوى المؤثرة على

1.2 معادلة عمق الماء الطبيعي (dn)

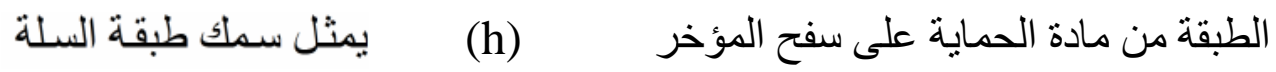

الصخرية من قعر الطبقة المحمية والى قعر العمق المفروض للمجرى.فبهذا تكون كتلة الطبقة لكل وحدة الطية

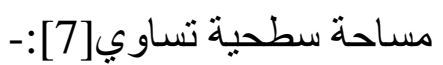

$M=a^{\prime \prime} \rho_{s} h$

... (1)

يتم الحصول عليها من العلاقة الآتية :

=

Ds $=r^{\prime}=b^{\prime} h$

... (2)

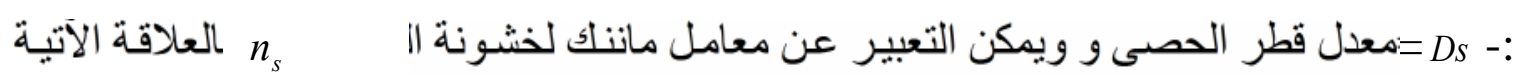

$n_{s}=0.153 \frac{\left(r^{\prime}\right)^{1 / 6}}{\sqrt{g}}$

... (3)

g=التعجيل الأرضي وان السرعة في القنوات المفتوحة تساوي: 
$V=\frac{1}{n} R^{2 / 3} S^{1 / 2}$

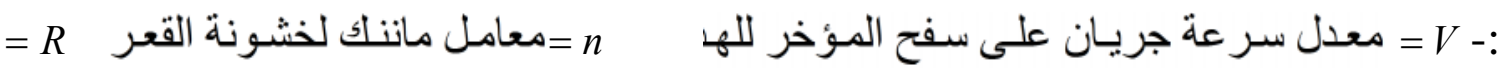

نصف القطر الهيدروليكي ويمكن التعبير عن التصريف لكل وحدة عرض (q ) للقنـوات العريضـة (

$$
\left(R \approx d_{n}\right.
$$

$q=\frac{1}{n} \times d_{n}^{5 / 3} \times S^{1 / 2}$

$\ldots(5)$

المعادلتين (5) (6) بينتج:

$d_{n}^{5 / 3}=n \times g^{1 / 2} \times \frac{d_{c}^{3 / 2}}{S^{1 / 2}}$

dn-: العمق الطبيعي للماء ويمكن حساب (q)

$q=g^{1 / 2} \times d_{c}^{3 / 2}$

... (6)

$\ldots(7)$
: ئ $\left(n=n_{s}\right)$
وبتعويض المعادلة (3)

$\therefore d_{n}=C\left[\frac{r^{\prime 1 / 10} d_{c}^{9 / 10}}{S^{3 / 10}}\right]$

... (8)

$0.3242=0.153)^{3 / 5}=C$ - 


\section{2 تحليل القوى المؤثرة على سفح المؤخر المسببة للفشل:}

: $\quad$ (F)

$F=W_{1} \sin \theta+W_{w g} \sin \theta+W_{w} \sin \theta+F_{s} \cos \theta$

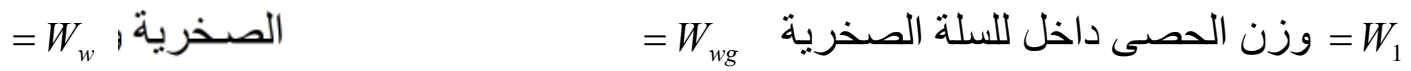

$$
\begin{aligned}
& \text { فوق السلة الصخرية }
\end{aligned}
$$

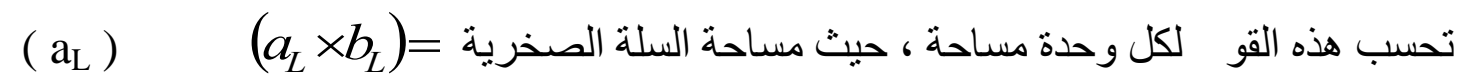
السلة الصخرية و ( bR ) طول السلة الصخرية .كل هذه القو و واجه مقاومة ممثلة بقوة الاحتكالك (FR)

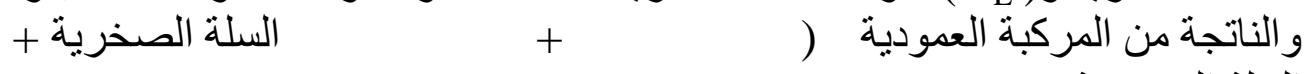
السلة الصخرية

$F R=\left(W_{1} \cos \theta+W_{w g} \cos \theta+W_{w} \cos \theta-F_{s} \sin \theta\right) \times \tan \phi_{g}$

: = = ز اوية ميل السفح المؤخر و و=ز اوية الوضع للسلة الصخرية.

$$
=
$$

$\left(a^{\prime \prime} \gamma_{s} h+\left(1-a^{\prime \prime}\right) \gamma_{w} h+\gamma_{w} d_{n}\right) \times \sin \theta+I \gamma_{W} h \cos \theta=$

$\left.\left[\left(a^{\prime \prime} \gamma_{s} h+\left(1-a^{\prime \prime}\right) \gamma_{w} h+\gamma_{w} d_{n}\right) \cos \theta-I h \gamma_{w} \sin \theta\right)\right] \tan \phi_{g}$

(11)

$I=\frac{d h}{d l}$ 


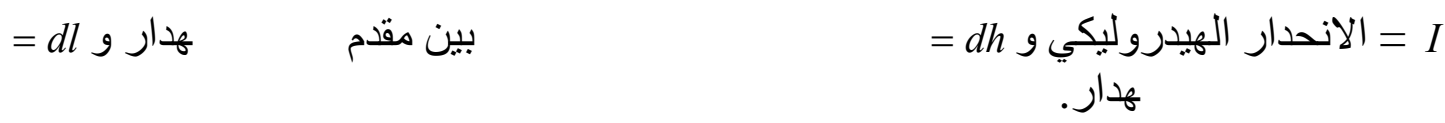

$$
\begin{aligned}
& \left(a^{\prime \prime}\left(\frac{\gamma_{s}}{\gamma_{w}}-1\right) h+h+d_{n}\right) S+I h=\left(a^{\prime \prime}\left(\frac{\gamma_{s}}{\gamma_{w}}-1\right) h+h+d_{n}\right) \tan \phi_{g}-\operatorname{IhS} \tan \phi_{g} \\
& s=\frac{\sin \theta}{\cos \theta} \\
& \text { A } \\
& a^{\prime \prime}\left(\frac{\gamma_{s}}{\gamma_{w}}-1\right) \\
& \frac{d_{n}}{h}\left(\tan \phi_{g}-S\right)=K_{2}\left[\frac{S}{\tan \phi_{g}}+\frac{I}{K_{2}}+\frac{I S}{K_{1}}-1\right] \\
& \text {... (13) } \\
& =K_{1}, K_{2}-: \\
& K_{1}=(1+A) \\
& K_{2}=(1+A) \tan \phi_{g} \\
& \text { : (13) ينتج } \\
& \text { وبتعويض المعادلة (8) } \\
& \left(\frac{d_{c}}{h}\right)=\left[\frac{K_{3} S^{3 / 10}}{\left(\tan \phi_{g}-S\right)}\left(\frac{S}{\tan \phi_{g}}+\frac{I}{K_{2}}+\frac{I S}{K_{1}}-1\right)\right]^{10 / 9} \\
& K_{3}=\frac{K_{2}}{C b^{\prime 0.1}}
\end{aligned}
$$


3-العمل المختبري

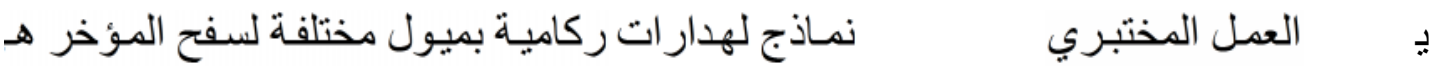

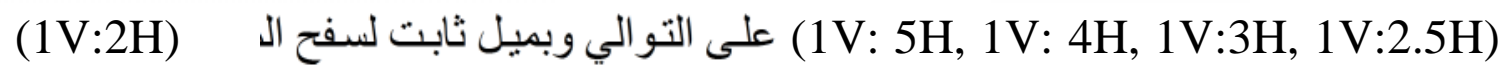

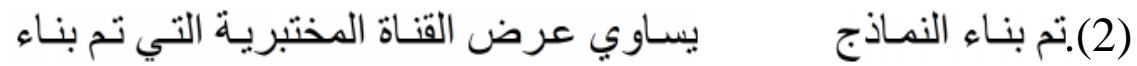

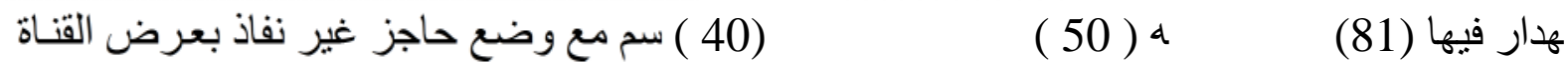
ع من مادة البلاستيك و (6 ) ملم تم تثبيته في إطار حديدي مثبت

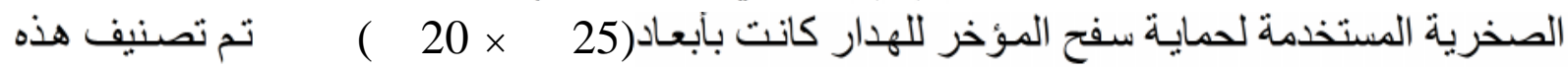
مجاميع اعتمادأ على ميول سفح المؤخر للهدا المشار إليه أعلاه. كل مجموعة التضمن

$$
\text { ( } 11.1115 .922 .25=D s)
$$

الفحص أربع مر ات للنموذج الو احد وكما يأتي(

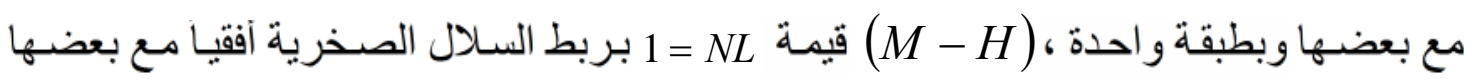

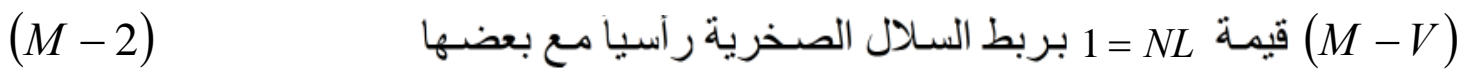

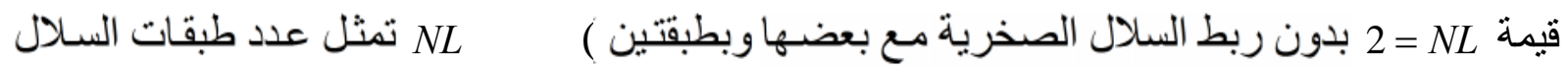

الهدار

(1) يبين بعض الأبعاد المهمة في إنشاء الهـاء
.[11]

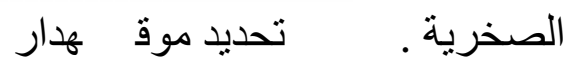

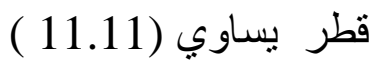

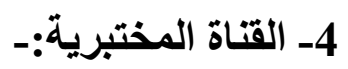

$0.81)$

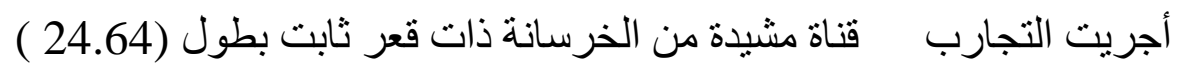

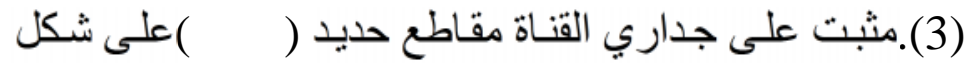

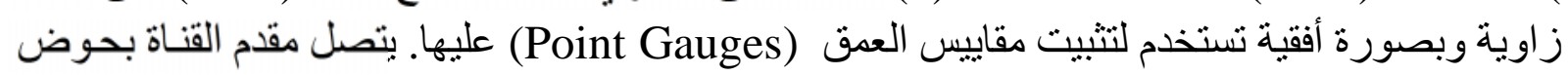

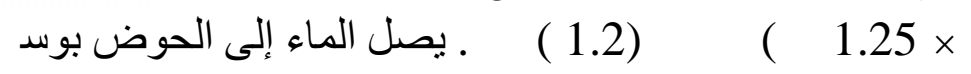

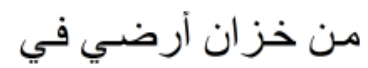
(15.24 ) سم مثبت عليه صمام للسبطرة على التصريف ويد

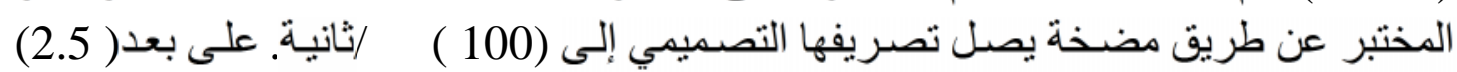

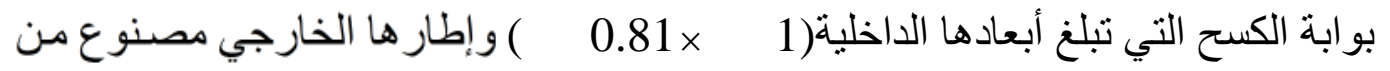

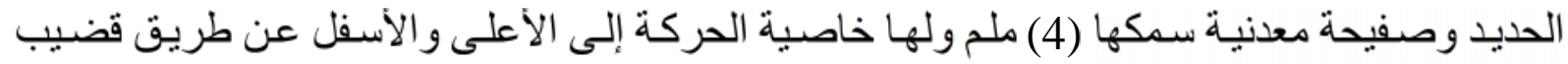

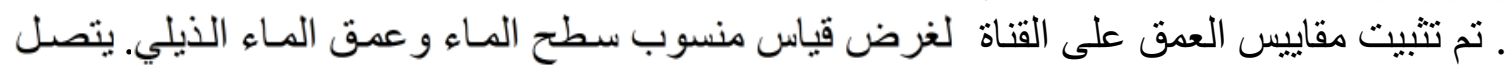

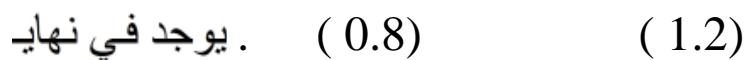

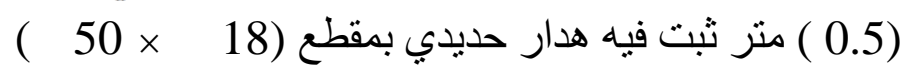

بنهاية القناة حوض التصريف (1.84)

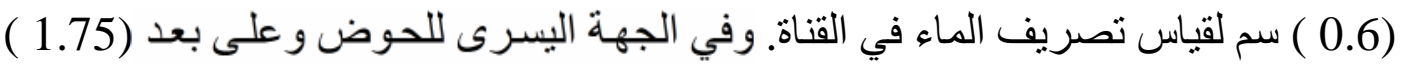

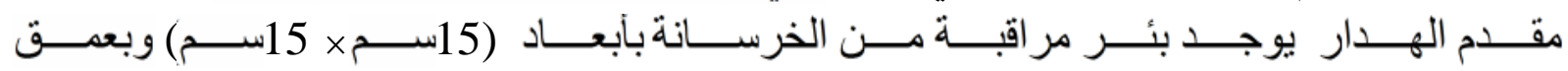


نوري : دراسة مختبرية لحماية سفح المؤخر للهارات الركامية باستخدام السلال الصخرية

(0.6) متر ذو وجه زجاجي لكي يمكن ملاحظة وقياس منسوب سطح الماء فوق الهدار بوساطة مقياس

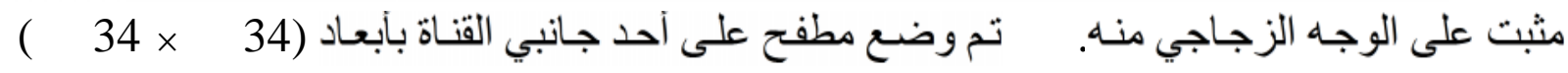
(1.94 ) متر من بداية القناة

تصريف مستقر مع الزمن وكما مبين في الثنكل (3). 


\section{5-مواصفات المواد المستخدمة في التجارب :-}

الهار و السلال الصخرية هي من الحصى النهري

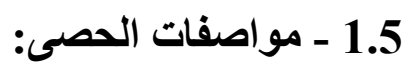

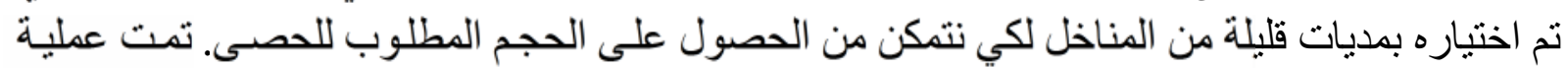

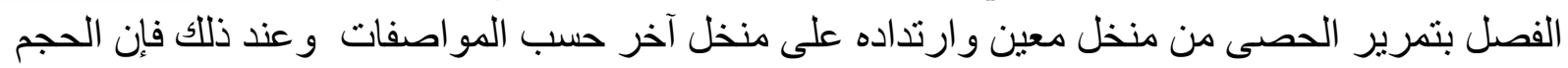

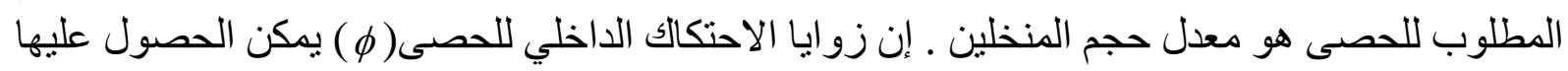

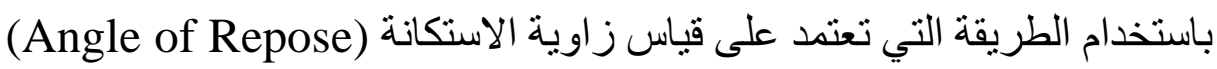
.[12] (2) وقد كانت ضمن الحدود التي أثنار إليها الباحثان سايمونز الانية 2.5 مواصفات السلال الصخرية:-

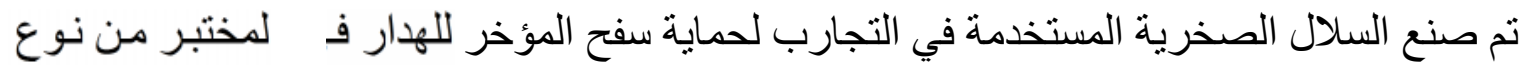

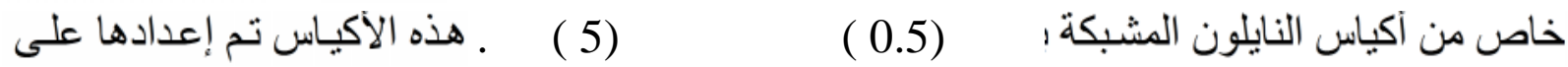

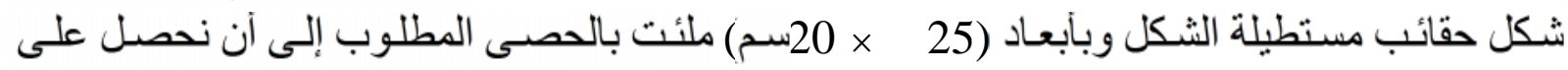

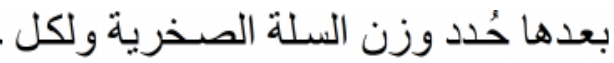

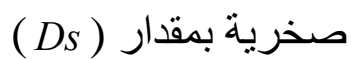

ـ إن طريقة وضع السلال الصخرية على سفح المقدم والمؤخر كانت على النحو الآتي:

في بداية سفح المؤخر أربعة سلال صخرية ثم يليها في

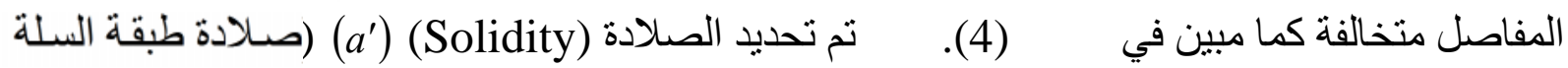
الصخرية ) لكل نوع من الحصى من المعادلة الآتية[7]:-

$a^{\prime}=\frac{m}{a_{L} b_{L} \rho_{s} h}$

(3) - - - $=$

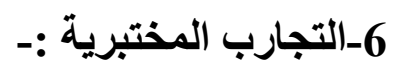

تتلخص خطو ات إجر اء التجارب المختبرية بما يأتي:-
) و انتهاءُ بمقدمـه ( )

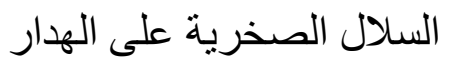 $-1$ السلال الصخرية مع بعضها على سفح المقل المقاد و القمة.

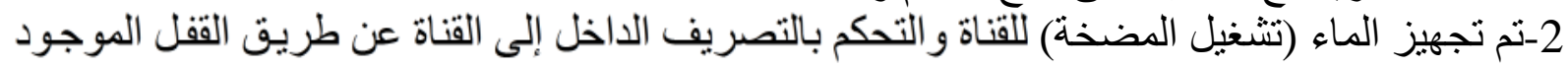

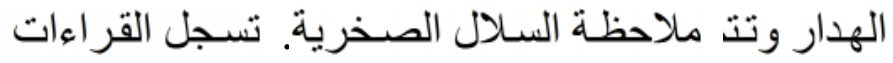

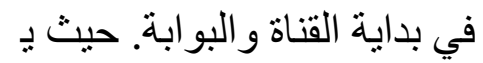


الماء الذيلي و ارتفاع الماء فوق الهدار

المطلوبة وهي

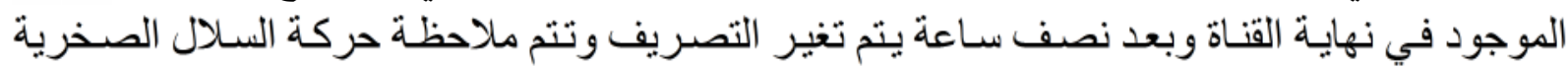
يقة وكذلك حركة الحصى الموجود داخل السلة الصخرية وتستمر التجربة بتغير التصريف كل كل

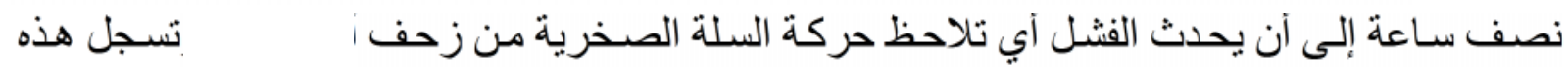

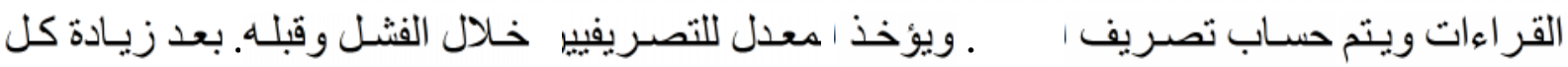

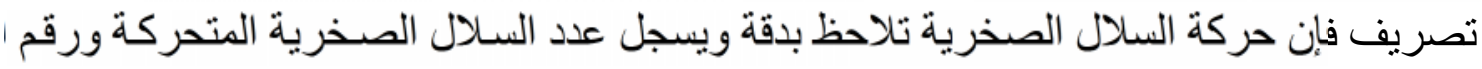

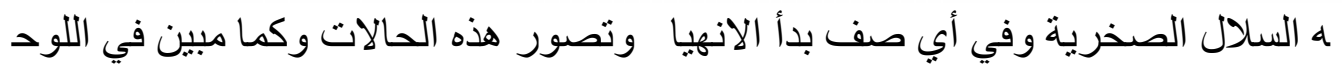

\section{7 - تحليل ومناقشة التتائج المختبرية}

العو امل المؤثرة على تصريف الفنشل

Downstream Slope

1.1.7

إن إحدى الأهداف الأساسية للبحث هي دراسة تأثثر مبل سفح المؤخر على تصريف الفشل

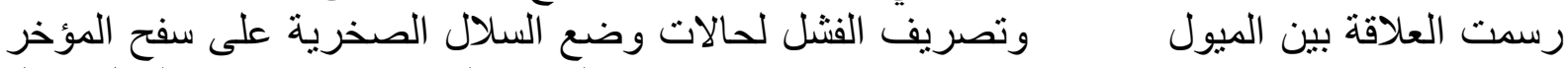

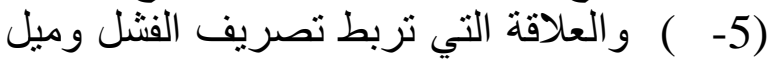

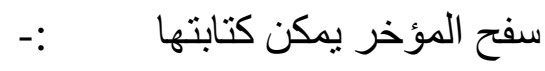

$q_{f}=a_{1} S^{b_{1}}$

... (16)

$$
=b_{1}, a_{1}
$$

ب $=q_{f}:$

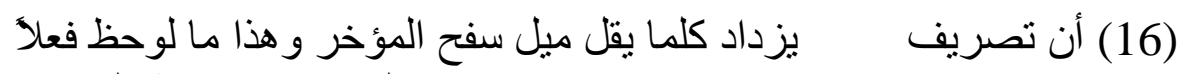

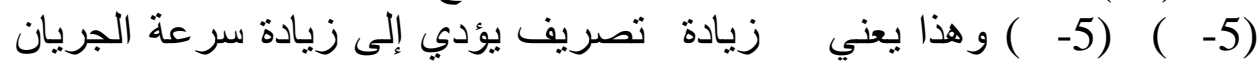
ويلاحظ

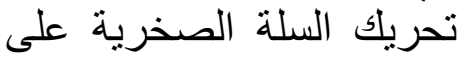

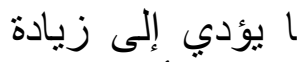

و ويلاحظ من الجدول (4) أن العلاقة التي تربط بين تصريف الفتل وميل سفح المؤخر علاقة عكسية.

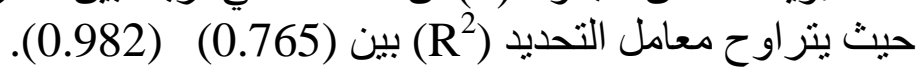

\subsection{7}

\section{للسلال الصخرية بثلاث}

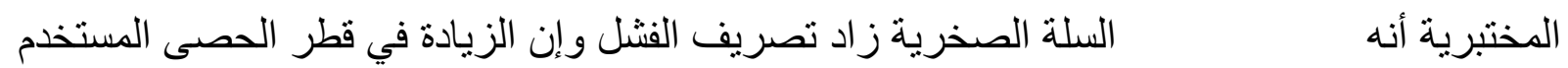

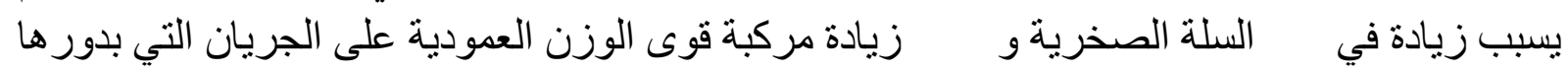

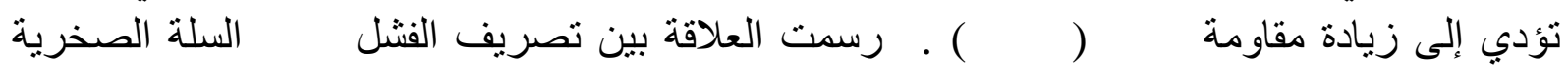

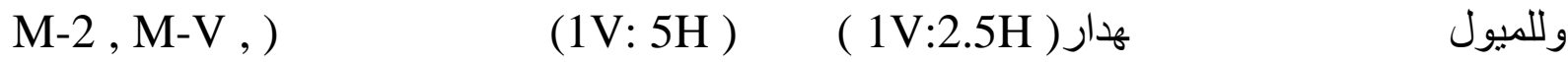

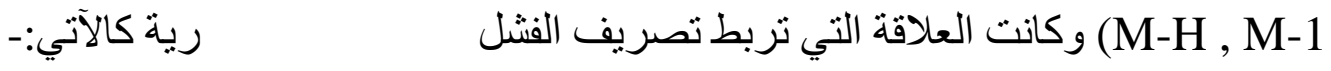


$q_{f}=a_{2} W_{g}^{b_{2}}$

... (17)

$$
\begin{aligned}
& \text { = }=W_{g} \quad=b_{2}, a_{2} \text { : السلة الصخرية }
\end{aligned}
$$

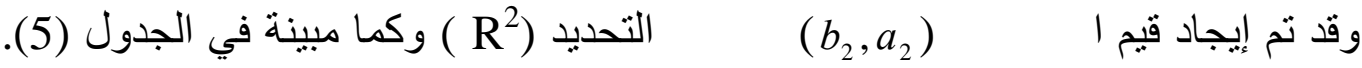

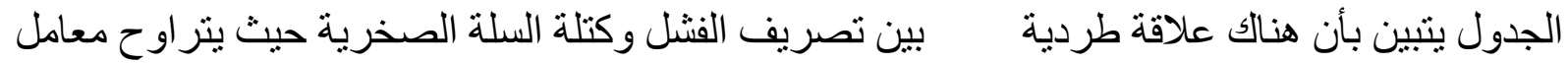

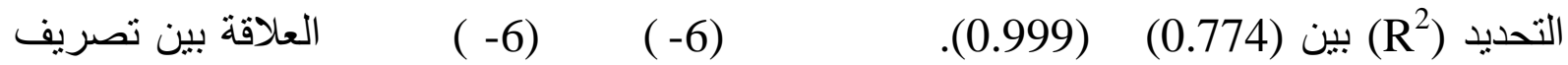

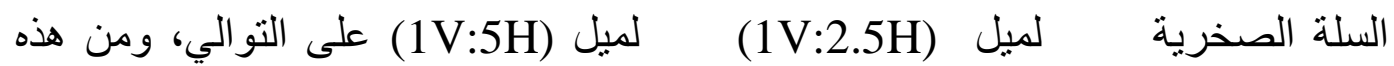
يتبين أن تصريف الفثل يزداد بزيادة السلة الصخرية ونقصان الميل.

3.1.7 ربط السلال الصخرية مع بعضها:-

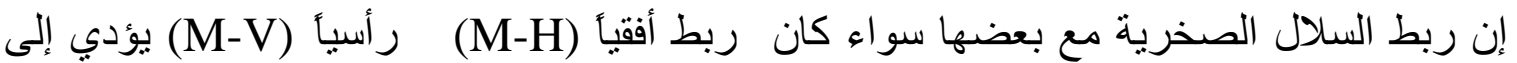

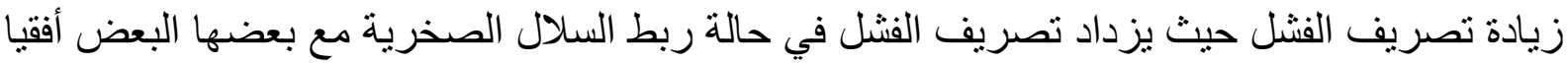

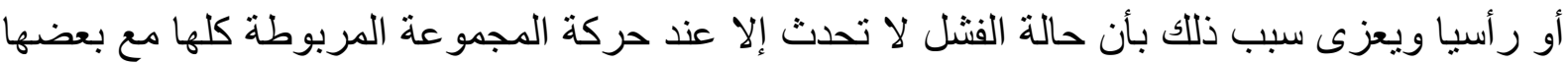
م الهدار تحت السلال الصخرية وهذا يحتاج إلى تصاريف أكبر للحدوث لالهئ لاسيما

\section{7 معادلات تصريف الفشل لوضع السلال الصخرية:-}

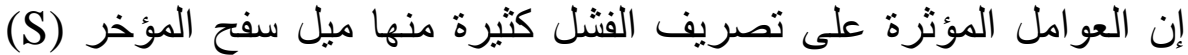

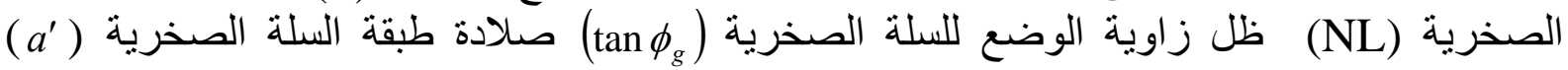
التعجيل الأرضي (g) $\quad$ الكتلية

$$
\begin{aligned}
& \text { (ب). إن تصريف الفثل للهدار } \\
& \left(\rho_{s}-\rho_{w}\right)
\end{aligned}
$$

المحمي بالسلال الصخرية يكون دالة لهذه المتغير ات.

$q_{f}=f_{1}\left(S, N L, \tan \phi_{g}, a^{\prime}, D s, g, \rho_{w}, \rho_{s}-\rho_{w}, \mu\right)$

عملية التحليل وباستخدام نظريـة باي [Pi-Theorem] يمكن صياغة العلاقة (18) 
$\frac{q_{f}}{g^{1 / 2} D s^{3 / 2}}=f_{2}\left(\frac{\rho_{s}-\rho_{w}}{\rho_{w}}, \operatorname{Re},(N L), \tan \phi_{g}, a^{\prime}, S\right)$

... (19)

= Re-:

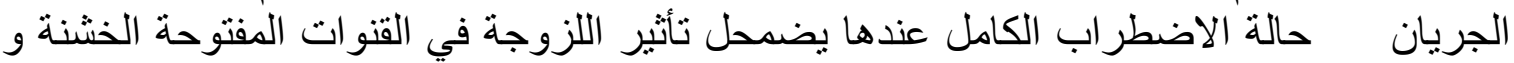
يمكن إهماله. وبإعادة ترتيب المتغير ات في المعادلة (19) يمكن كتابتها بالثكل الثل الآتي:-

$q_{f}=C_{s} g^{1 / 2} D s^{3 / 2}\left(\frac{\rho_{s}-\rho_{w}}{\rho_{w}} \times a^{\prime} \times \tan \phi_{g}\right)^{e_{1}}(N L)^{e_{2}}(S)^{e_{3}}$

(20)

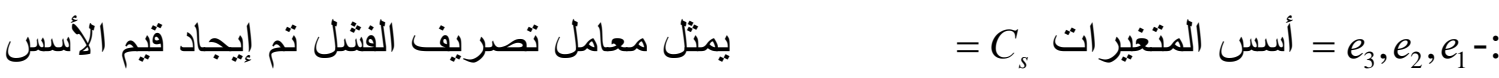

Nonlinear )

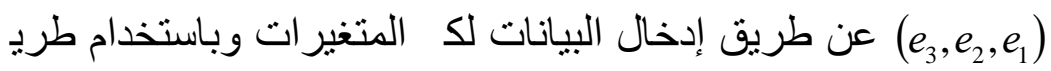

(SPSS VER 10)

(Regression -في حالة وضع السلال الصخرية على سفح المؤخر بشكل (M-1,M-2):

حيث إن قيمة $q_{f}=C_{s} g^{1 / 2} D s^{3 / 2}\left(\frac{\rho_{s}-\rho_{w}}{\rho_{w}} \times a^{\prime} \times \tan \phi_{g}\right)^{2.56}(N L)^{0.28}(S)^{-1.4}$
$0.904=\left(\mathrm{R}^{2}\right)$ و معامل التحديد $0.981=\mathrm{C}_{\mathrm{s}}$

(M-V) وكذلك تم إيجاد معادلات لحالة الربط الأفقي(M-H)

:(M-H)

$q_{f}=C_{s} g^{1 / 2} D s^{3 / 2}\left(\frac{\rho_{s}-\rho_{w}}{\rho_{w}} \times a^{\prime} \times \tan \phi_{g}\right)^{2 . .6}$

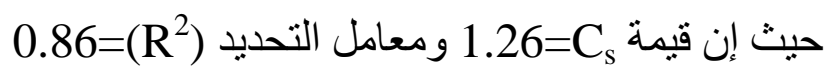
:(M-V) 
$q_{f}=C_{s} g^{1 / 2} D s^{3 / 2}\left(\frac{\rho_{s}-\rho_{w}}{\rho_{w}} \times a^{\prime} \times \tan \phi_{g}\right)^{2.1}(S)^{-0.98}$

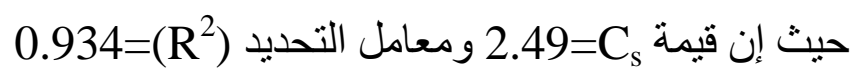

\section{7 زيادة نسبة تصريف الفشل مع عدد الطبقات}

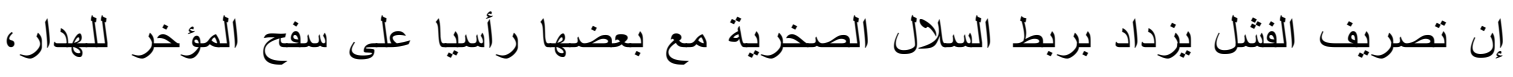
(6) يوضح النسبة المئوية لزيادة تصريف الفنل مع حالات وضع وربط ليط السلال الصخرية.

\section{7 العلاقة بين تصريف الفشل وقطر الحصى المستخدم}

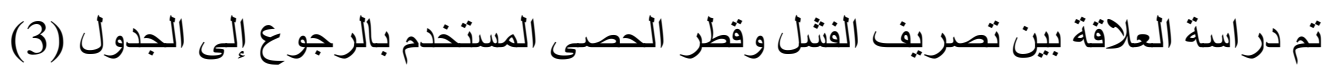
(23 22 21

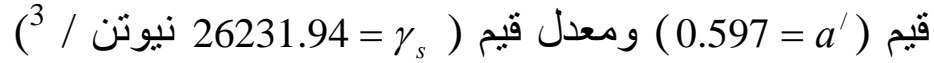

1V:4H 1V:3H 1V:2.5H) رسم العلاقة بين تصريف الفشل وقطر الحصى لكافة الميول

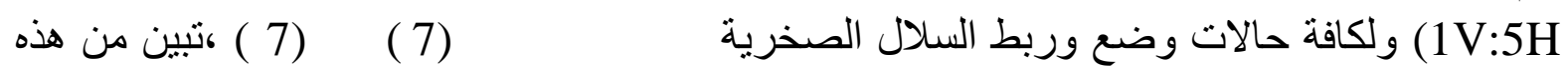

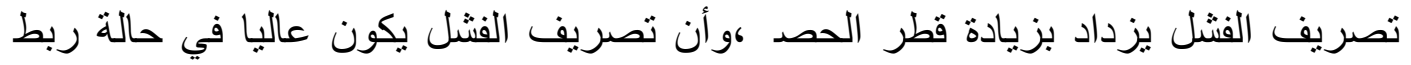

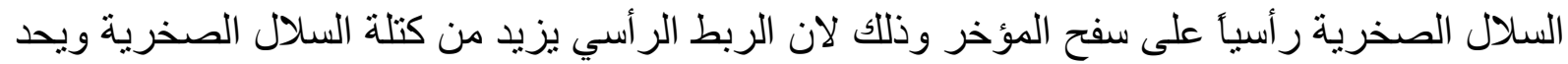

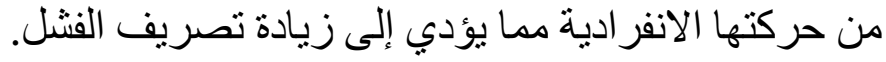

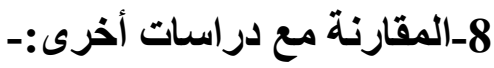

لآجل المقارنة مع دراسات سابقة تم رسم العلاقة بين تصريف الفشل وقطر الحصى المستخدم لحالة وضع السلال الصخرية بطبقتين (M-2) وللميل (1V:4H) مع نتائج تصريف الفنشل للباحث داؤد

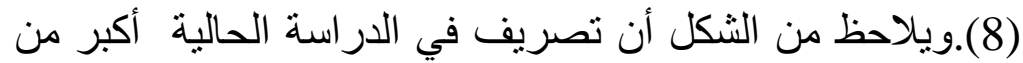

(Dawood ,1999) در اسة الباحث داؤد و هذا يدل على أن الهدارات الركامية الدحمية بالسلال الصخرية تكون كفاءتها أعلى الصى

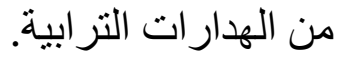




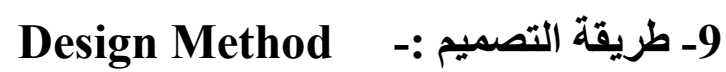

الأهداف الرئيسة لهذه الدراسة هي لحصول على طريقة تصميمية لحماية الهدارات الركامية

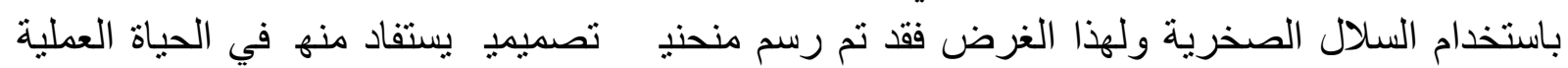
الطريقة

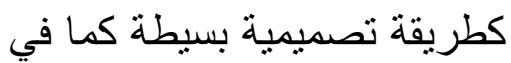

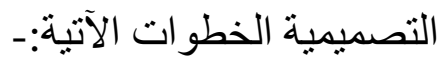

1- إجراء دراسة شاملة للموقع الذب سيقام فيه اله ويقدر معدل الجريان الأعظم المتوقع في ذلك

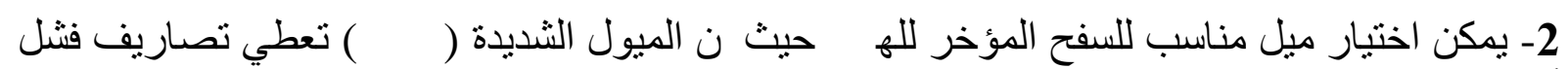
أقل من التصاريف التي تعطيها الميول المنبسطة و بينتها

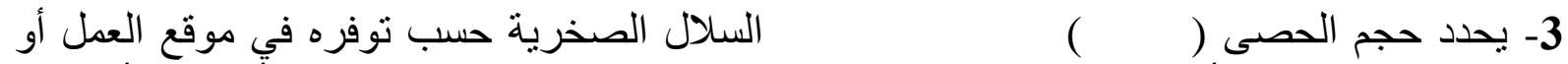

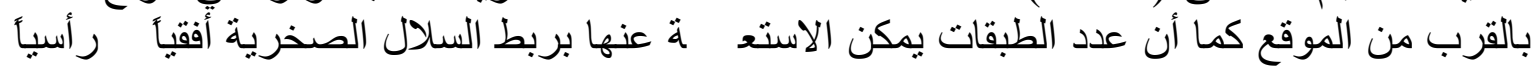

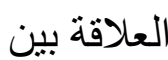
4- يمكن الحصول على تصريف الفنشل من المنحنيات (7 ) ) يساوي (2) بلإن

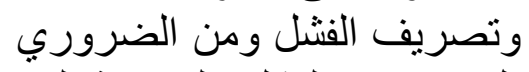

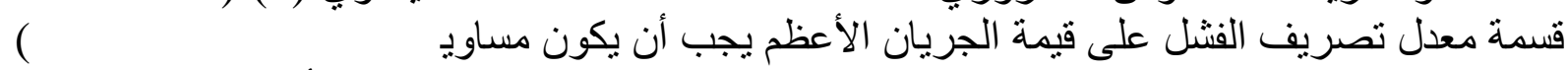

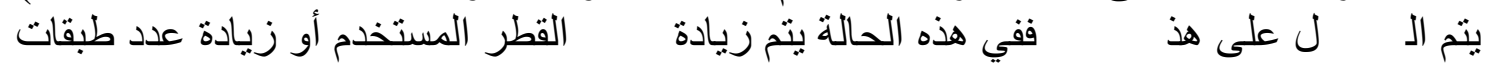

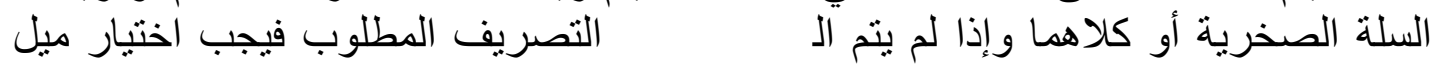
كوار.

ألرياضياتي مبين ولغرض تطبيقه فإنه يتطلب إيجاد المتغيرات من

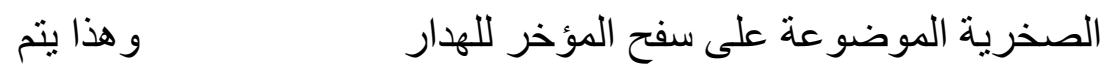

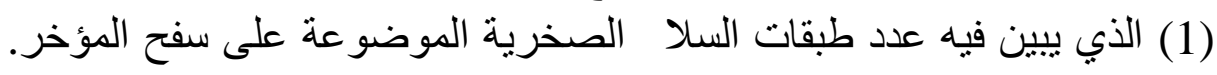

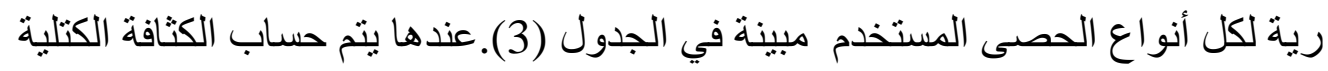

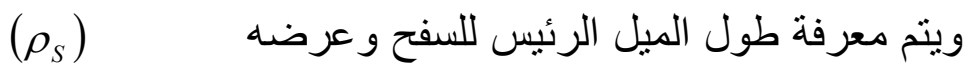

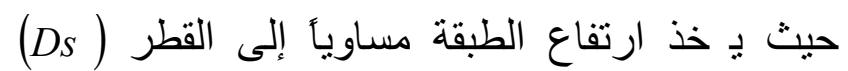

(3) بعدها ينم فرض قيمة

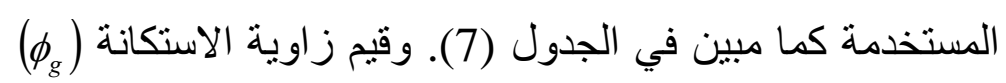

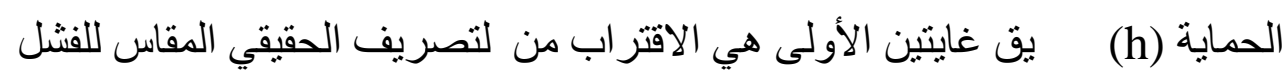

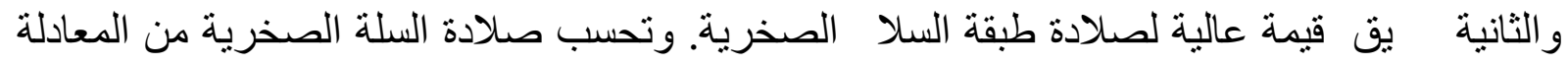
يكون $\left(r^{\prime}\right)$

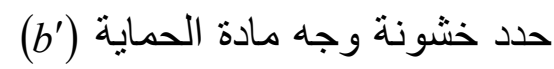

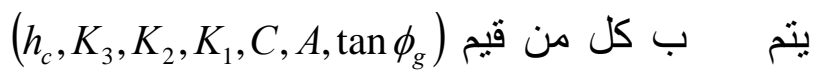

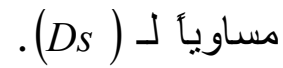

$$
\begin{aligned}
& \text { (14) و قيم تصريف } \\
& \text { (Matlab) }
\end{aligned}
$$

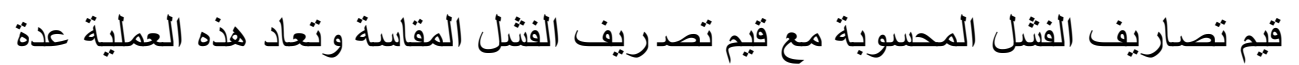

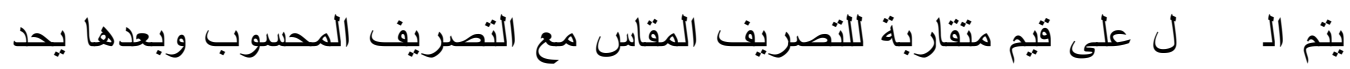
معامل تصحيح تصريف الفثل (C) بقسمة تصريف الفثل المقاس على تصريف الفثل المحسوب كما للفي 
(8).ولغرض الحصول على قيمة حقيقية لتصريف الفتل تضرب القيم المحسوبة للتصريف بـ
( المي ( 1V:3H, 1V:4H)
(8)
ت العلاقة بين تصريف
$\left(C_{f}\right)$ (1.05)
المقاس من التجارب المختبرية في الثكل (
14) وتصريف
. (Perfect agreement)
القيم

$\left(C_{f}\right)$

من هذا البحث تم التوصل الى الاستنتاجات الآتية:-

1- تم إيجاد العديد من المعادلات الوضعية التي تربط تصريف الفنشل مع ميل سفح المؤخر وكتلة السـلال

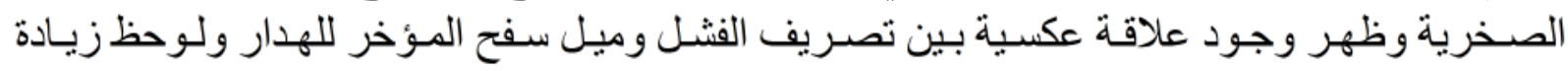
تصريف الفنل بزيادة وزن السلال الصخرية و عدد الطبقات ومعدل قطر الحصى .

لحساب تصريف الفشل لكافة حالات وضع وربط السلال الصخرية.

3- تم تقديم طريقة تصميمية مبسطة لحماية الهدارات الركامية باستخدام السلال الصخرية و على شكل

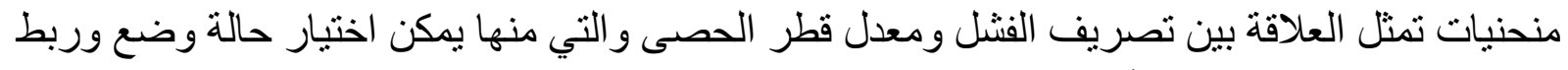

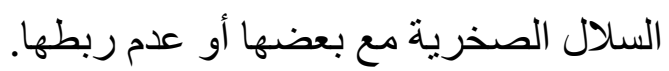

4- معرفة الخصائص الفيزيائية الظاهرية للنماذج الخمسة تم اشتقاق نموذج رياضياتي بناءً على

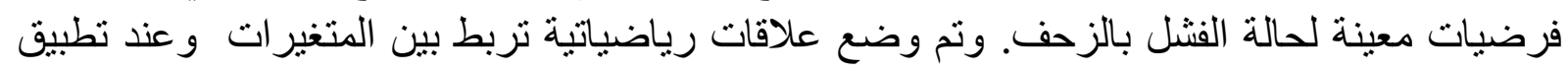
النموذج الرياضياتي تم الحصول على تصاريف قريبة من القيم المختبرية وللكتل الثلاثة من السلال

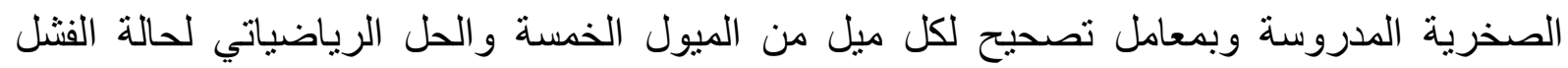
بالزحف هو الآتي:-

$\left(\frac{d_{c}}{h}\right)=\left[\frac{K_{3} S^{3 / 10}}{\left(\tan \phi_{g}-S\right)}\left(\frac{S}{\tan \phi_{g}}+\frac{I}{K_{2}}+\frac{I S}{K_{1}}-1\right)\right]^{10 / 9}$

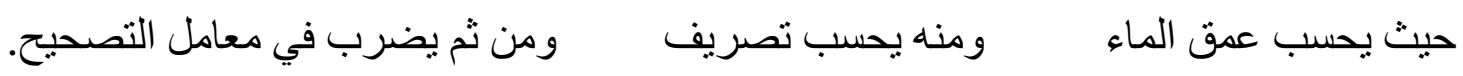


5- من ملاحظة التجـارب المختبريـة التـي نفذت تبين أن الفشل بـالزحف هو الأكثر حدوثنا من الفثـل

$$
\text { 6- ربط السلال الصخرية مع بعضها يمنعها من الحركة الانفر ادية و العشوائية. }
$$

[1]- AL- Mohammad, F.M.D.,1991,“ An Experimental Study of the Downstream Slope Stability with Overflow Rockfill Embankments", M.Sc.Thesis, Department of Irrigation and Drainage Engineering, Mosul University, Mosul, Iraq (In Arabic).

[2]- Parkin, A.K., Trollope, D., and Lawson, J.D., 1966, "Rockfill Structures Subject to Water Flow", Journal of Soil Mechanics and Foundation, Division., ASCE, November.

[3]- Freeman, G.E.,and Fischenich, J.C., 2000, "Gabion for Stream Banks Erosion Control" , Engineering Research and Progress, U.S. Army Engineer Research.

[4]- Stefano, C.S., and Ferro, V., 1998, "Calculating Average Filling Rock Diameter for Gabion- Mattress Channel Design", Journal of Hydraulic Engineering ASCE, Vol. 124, No. 9. PP. 975-978 September.

[5]- Yoon, T.H.,"Wire Gabion for Protecting Bridge Piers", 2005, Journal of Hydraulic Engineering, Vol. 131, Issue11, PP.942-949, November.

[6]- Maynord, S.T., 1995, "Gabion - Mattress Channel Protection Design", Journal of Hydraulic Engineering, ASCE, Vol. 121, No. 7, PP. 519-522, July.

[7]- Smith, K.V.H., 1979, "Wadi Surdud Model Testing of Weirs" Report on a Study Made in Collaboration with Sir William Halcrow and Partners, Swindan, February.

[8]- Stephenson, D., 1980, "The Stability of Gabion Weirs", International Water Power and Dam Construction Vol. 32, No.4 April, PP. 24-28.

[9]- Gerodetti, M., 1981, "Model Studies of an Over-Topped Rockfill Dam", International Water Power and Dam Construction, Vol. 33, No. 90.

[10]- Dawood, B.K,1999 ,"Laboratory Study on the Stability of Earth Weirs Protected by Gabions", Ph.D. Thesis, Department of Irrigation and Drainage Engineering, Mosul University, Mosul, Iraq (In Arabic).

[11]- ASTM standard, 1972, "Method for Particle Size Analysis of Soils" Designation, D422-63, PP. 112-122.

[12]- Simons, D.B., and Senturk ,F., 1976,"Sediment Transport Technology",Water Resources Publications, Fort Collin,Colorrado,U.S.A. 


\section{(1): الأبعاد المهمة في النماذج المستخدمة.}

\begin{tabular}{|c|c|c|c|c|c|}
\hline $1 \mathrm{~V}: 5 \mathrm{H}$ & $1 \mathrm{~V}: 4 \mathrm{H}$ & $1 \mathrm{~V}: 3 \mathrm{H}$ & $\begin{array}{c}1 \mathrm{~V}: 2.5 \\
\mathrm{H}\end{array}$ & \multicolumn{2}{|l|}{ 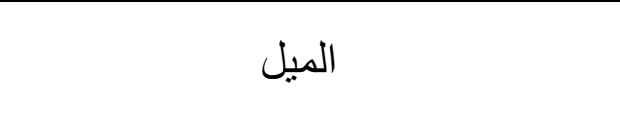 } \\
\hline 2.5 & 2.0 & 1.50 & 1.25 & المسافة الأفقية $\quad$ ( ) ( ) & 1 \\
\hline 0.5 & 0.5 & 0.5 & 0.5 & المسافة الرأسية ( ) & 2 \\
\hline 2.55 & 2.06 & 1.58 & 1.346 & طول الميل الرئيسي لسفح المؤخر( & 3 \\
\hline 10.2 & 8.24 & 6.32 & 5.38 & & 4 \\
\hline 40.8 & 32.96 & 25.28 & 21.536 & عدا السلال الصخرية على السفح & 5 \\
\hline 81.6 & 65.92 & 50.56 & 43.04 & عداد السلال الصخرية على السفح & 6 \\
\hline 11.31 & 14.04 & 18.44 & 21.8 & زاوية الميل ( & 7 \\
\hline
\end{tabular}

في الهدار و السلة الصخرية

\begin{tabular}{|c|c|c|c|c|}
\hline 0 & $\begin{array}{l}\mathrm{D}_{\mathrm{s}} \\
(\quad)\end{array}$ & يرتد على منذل & يمر من منخل & \\
\hline 32.0 & 11.11 & 9.52 & 12.7 & A \\
\hline 32.8 & 15.90 & 12.7 & 19.1 & B \\
\hline 34.0 & 22.25 & 19.1 & 25.4 & C \\
\hline
\end{tabular}


$(20 \times 25)$

الصخرية

(3)

\begin{tabular}{|c|c|c|c|c|c||}
\hline$\Phi_{\mathrm{g}}{ }^{0}$ & $a^{\prime}$ & $\begin{array}{c}\rho_{S} \\
{ }^{3} /\end{array}$ & $\left(^{3}\right)$ & $(\quad)$ & $\begin{array}{c}\mathrm{D}_{\mathrm{s}} \\
(\quad)\end{array}$ \\
\hline 34.2 & 0.716 & 2.638 & 398 & 1050 & 11.11 \\
\hline 35.4 & 0.576 & 2.664 & 458 & 1220 & 15.9 \\
\hline \hline 36.7 & 0.500 & 2.720 & 555 & 1510 & 22.25 \\
\hline 35.4 & 0.597 & 2.674 & 470.33 & 1260 & \\
\hline
\end{tabular}



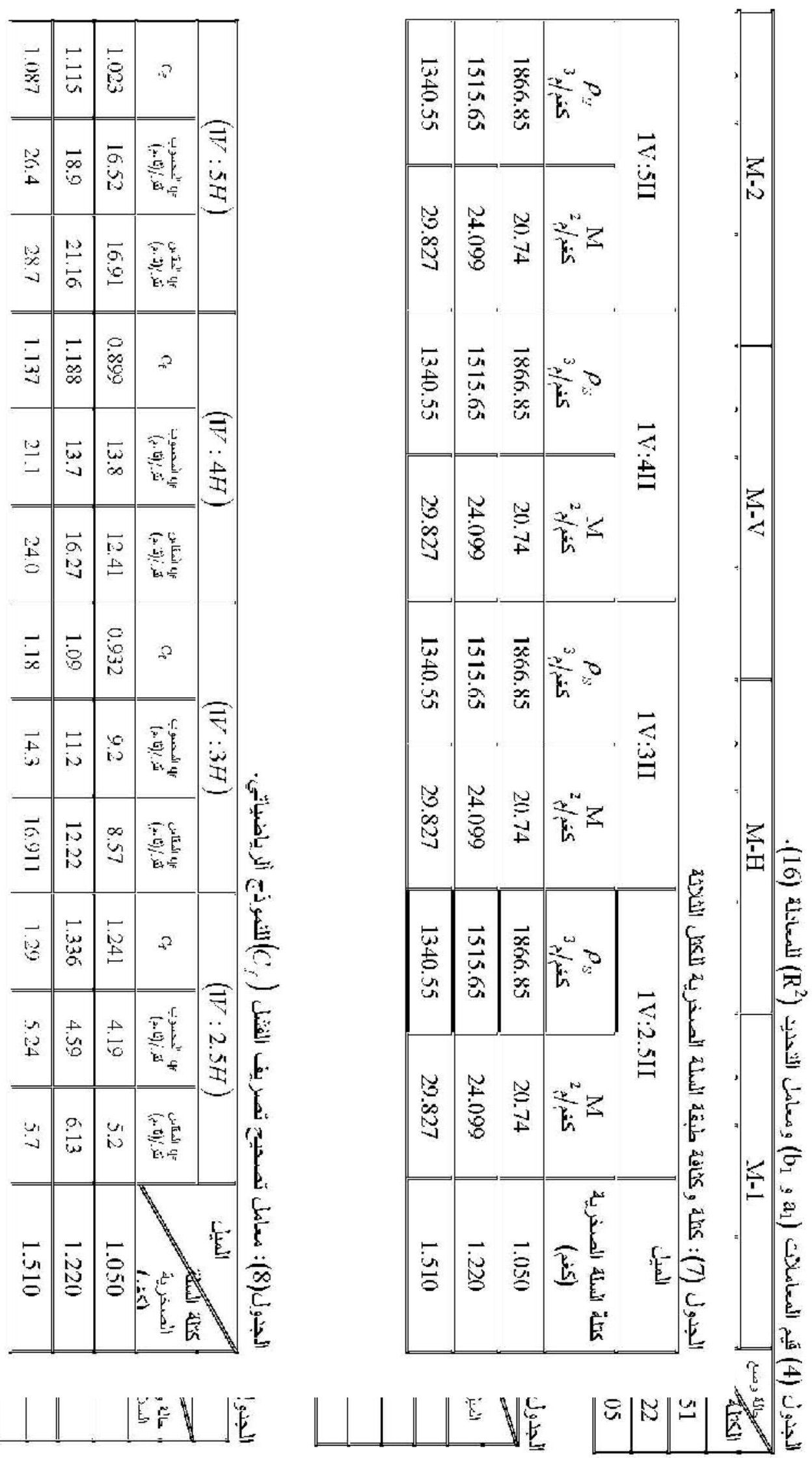


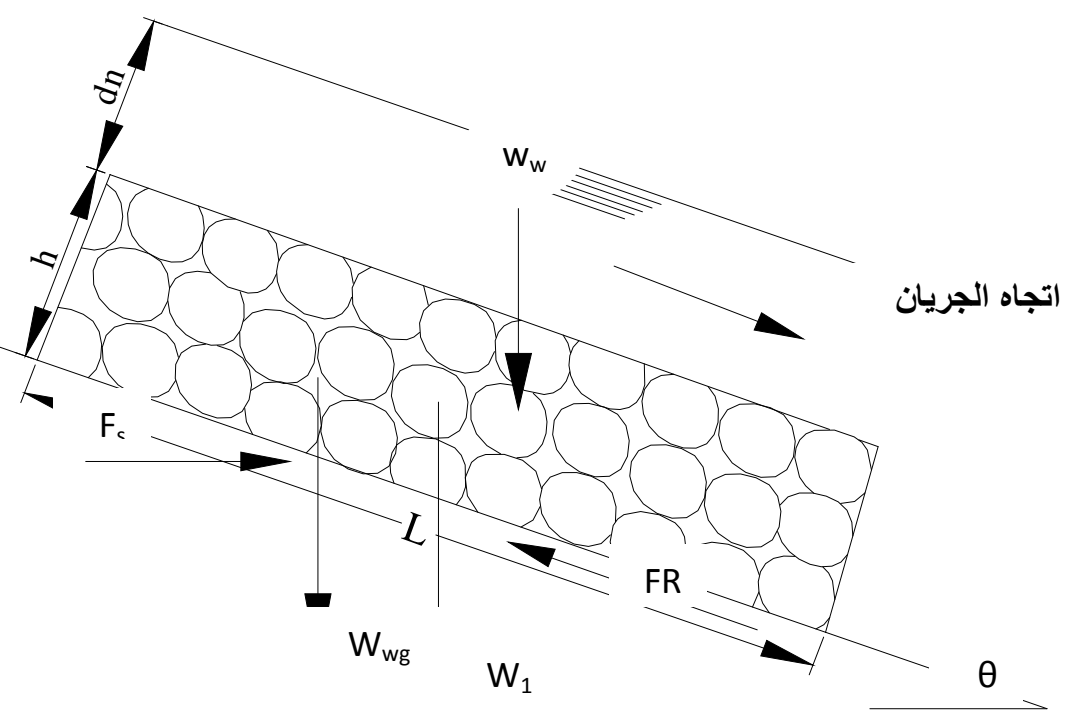

الثكل (1) القوى المؤثرة في طبقة السلة الصخرية

اتجاه الجريان

السلال الصخرية

سفح المقدم

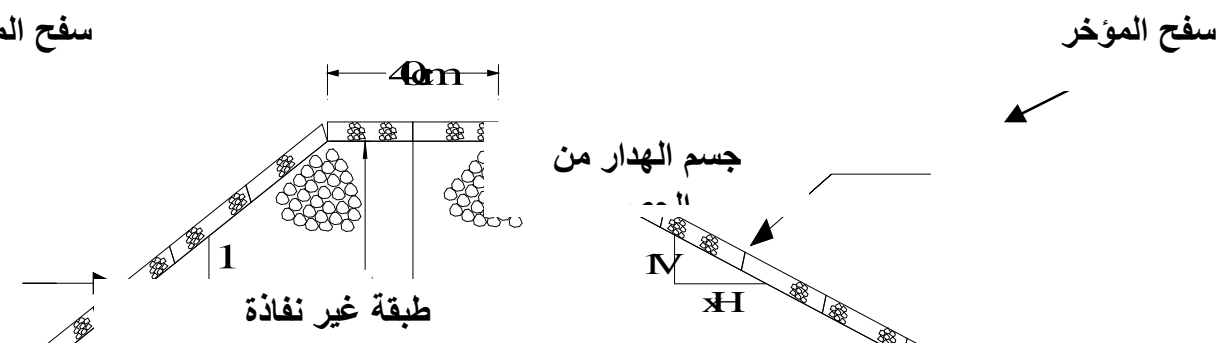

الثكل (2) مقطع طولي للهدار الركامي

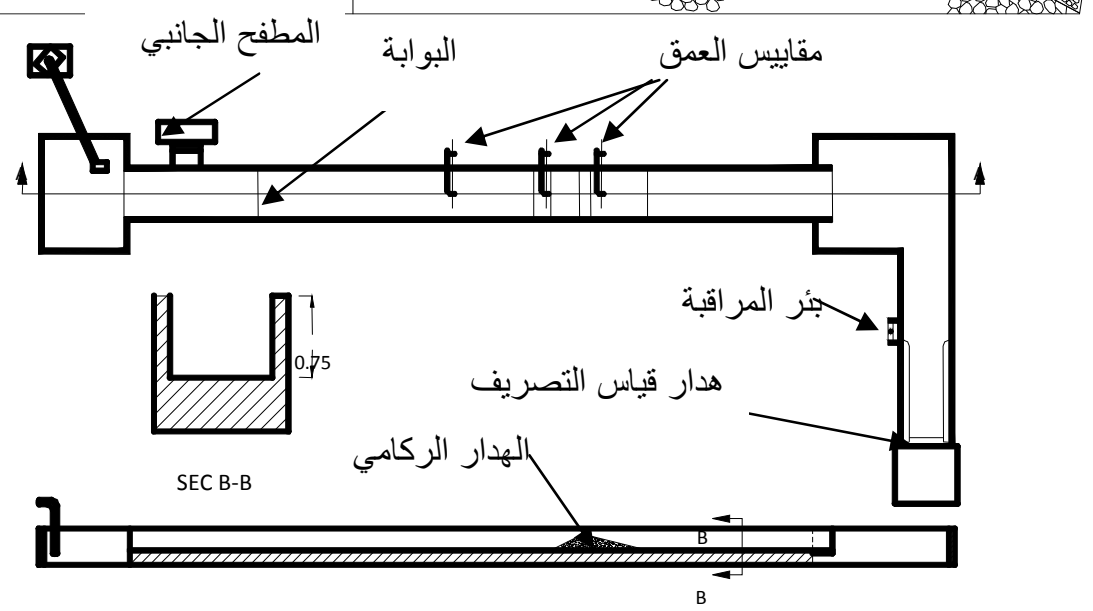

الثكل (3) القتاة المختبرية 

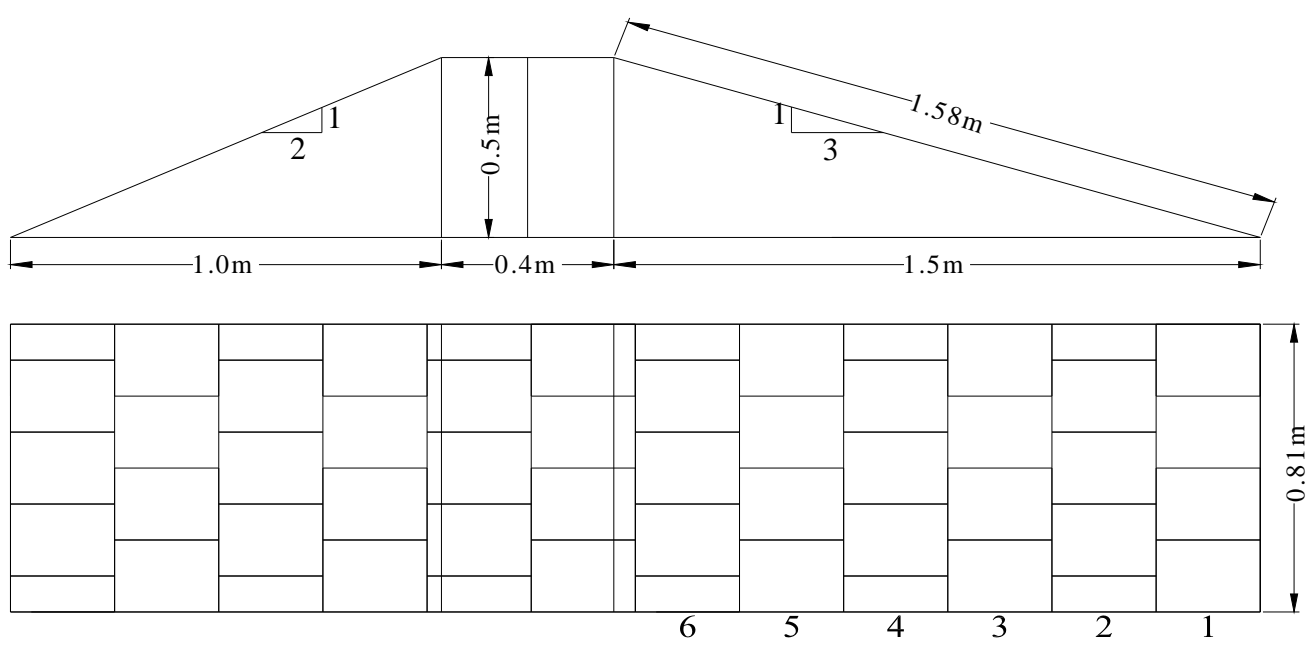

الثكل (4) منظر جانبي للهدار الركامي مع المسقط الافقي يوضح السلال الصخرية للميل (1V:3H)
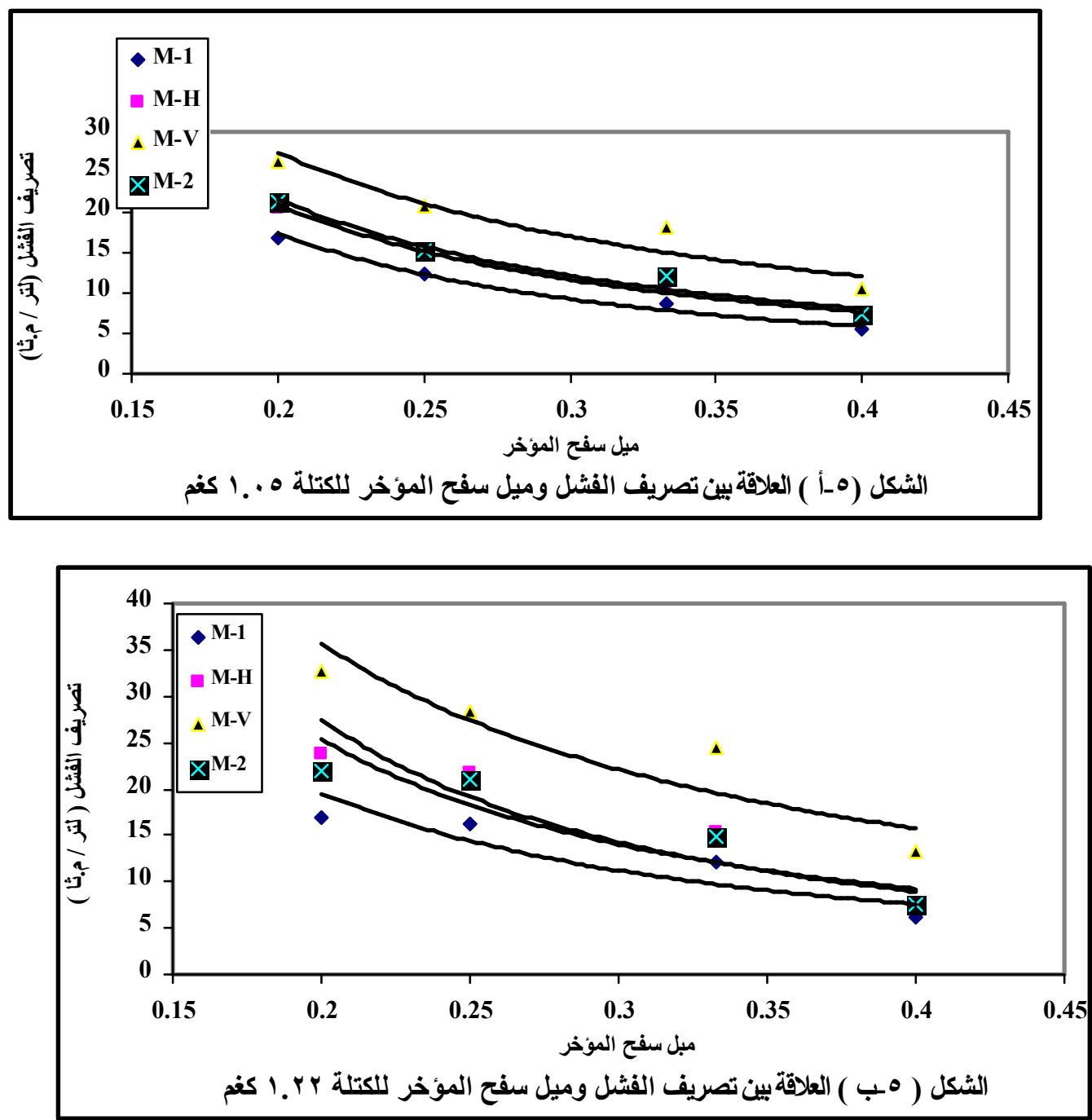

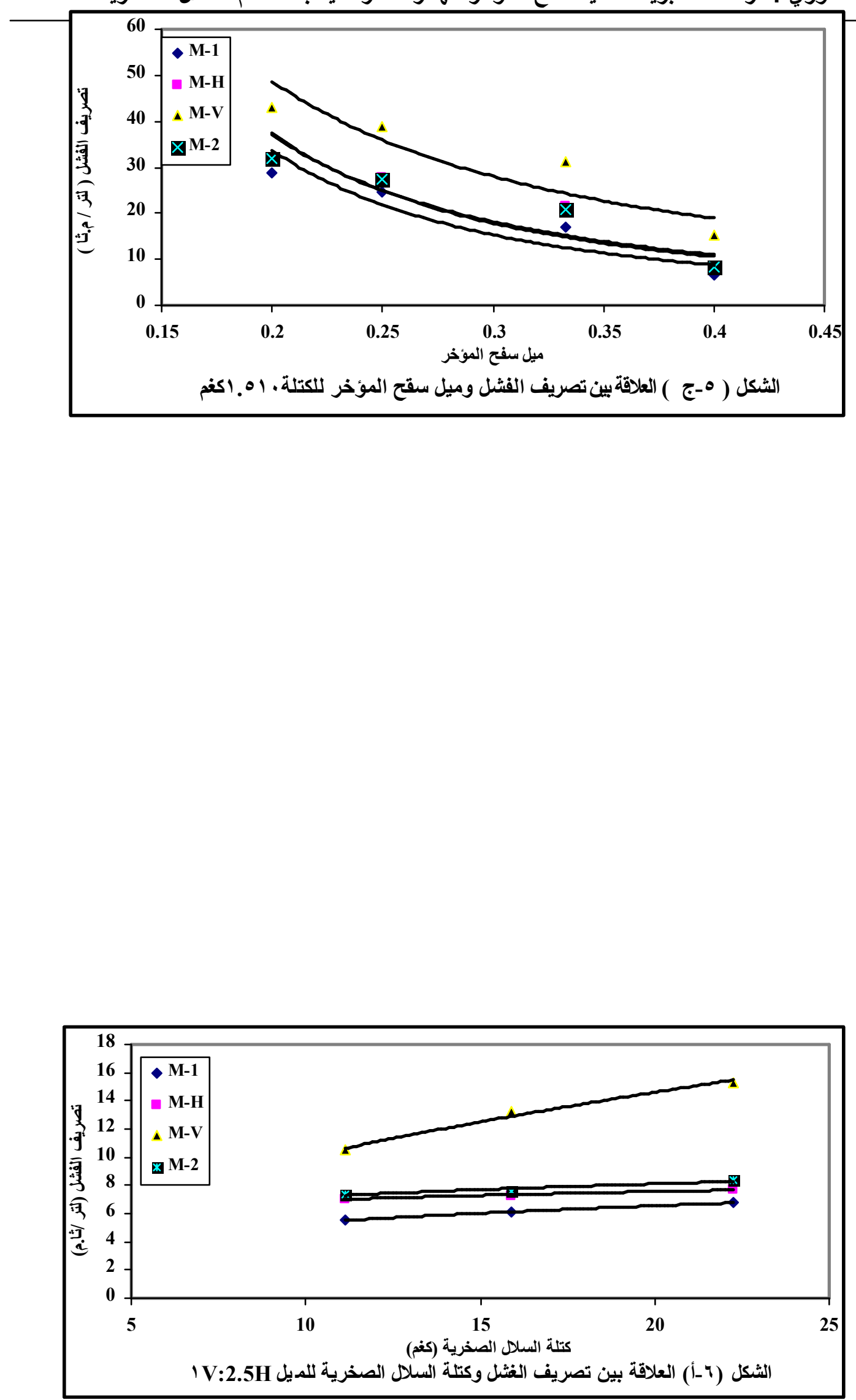


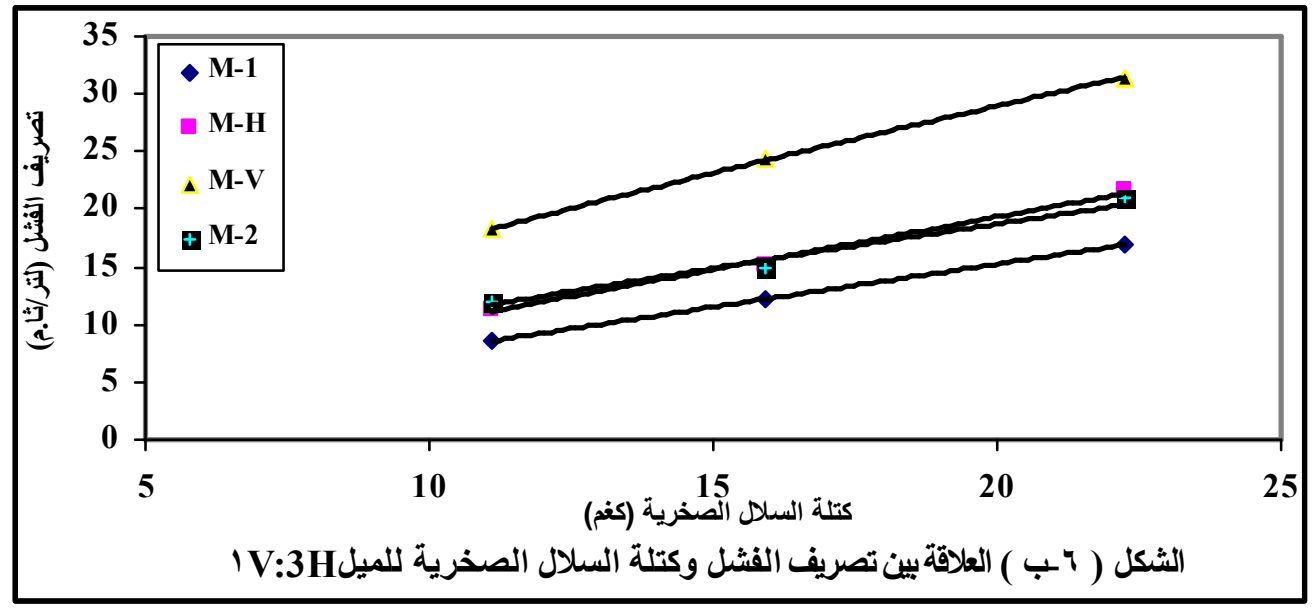



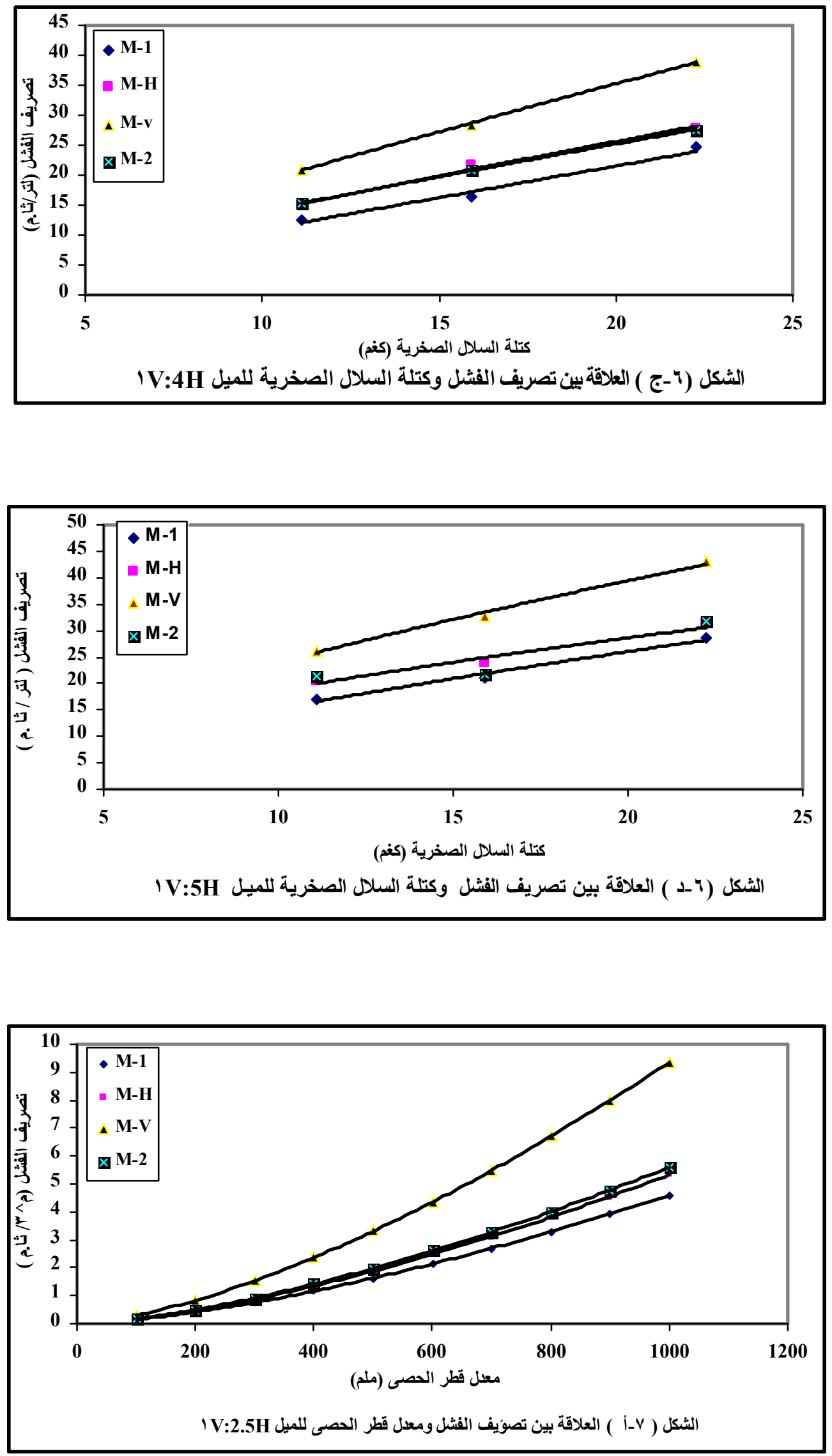
نوري : دراسة مختبرية لحماية سفح المؤخر للهارات الركامية باستخدام السلال الصخرية
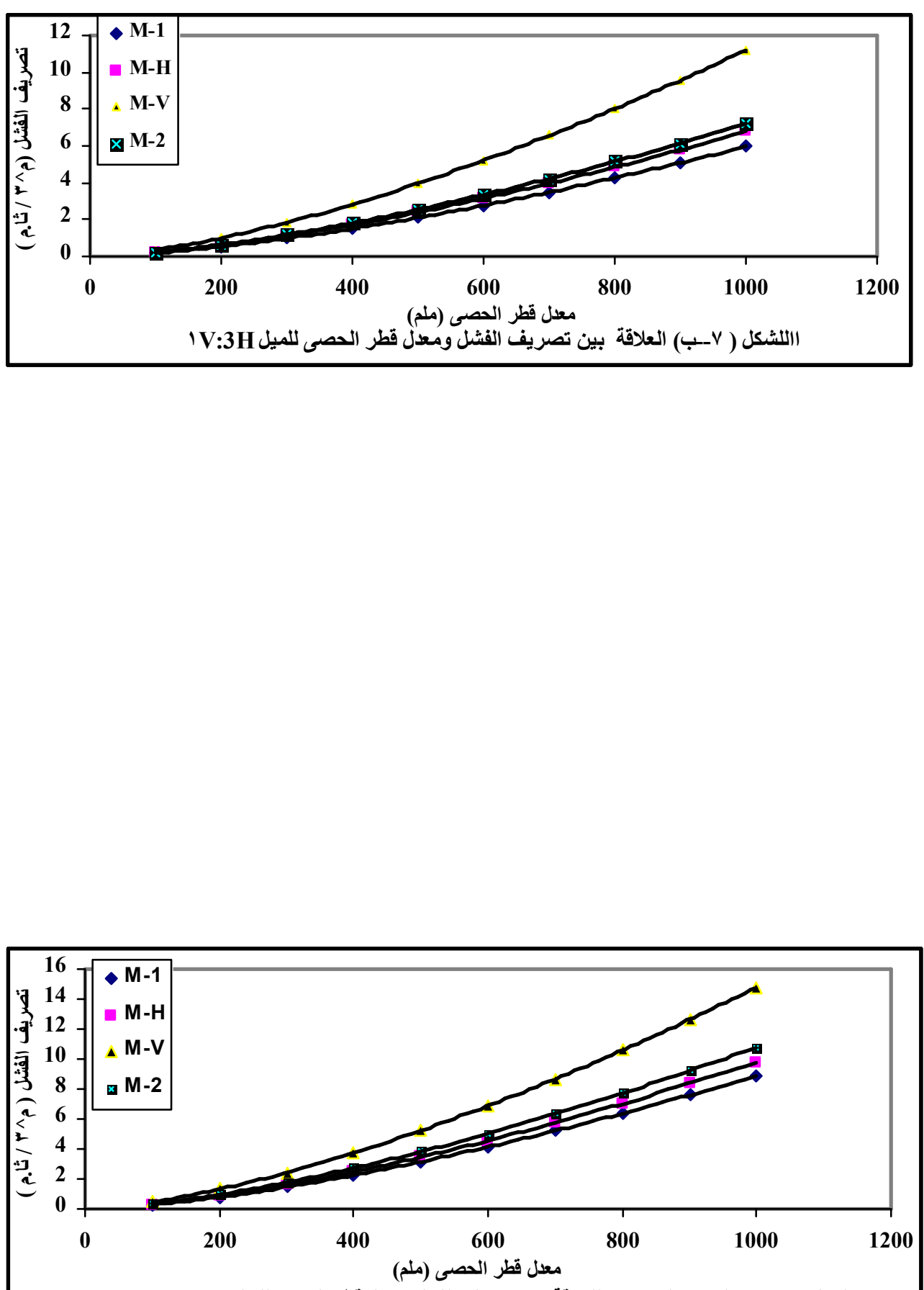

l V:4H الثكل ( V- ج ) المنحى التصميمي للعلاقة بين تصريف الفشل ومعل قطر الحصى للميل 


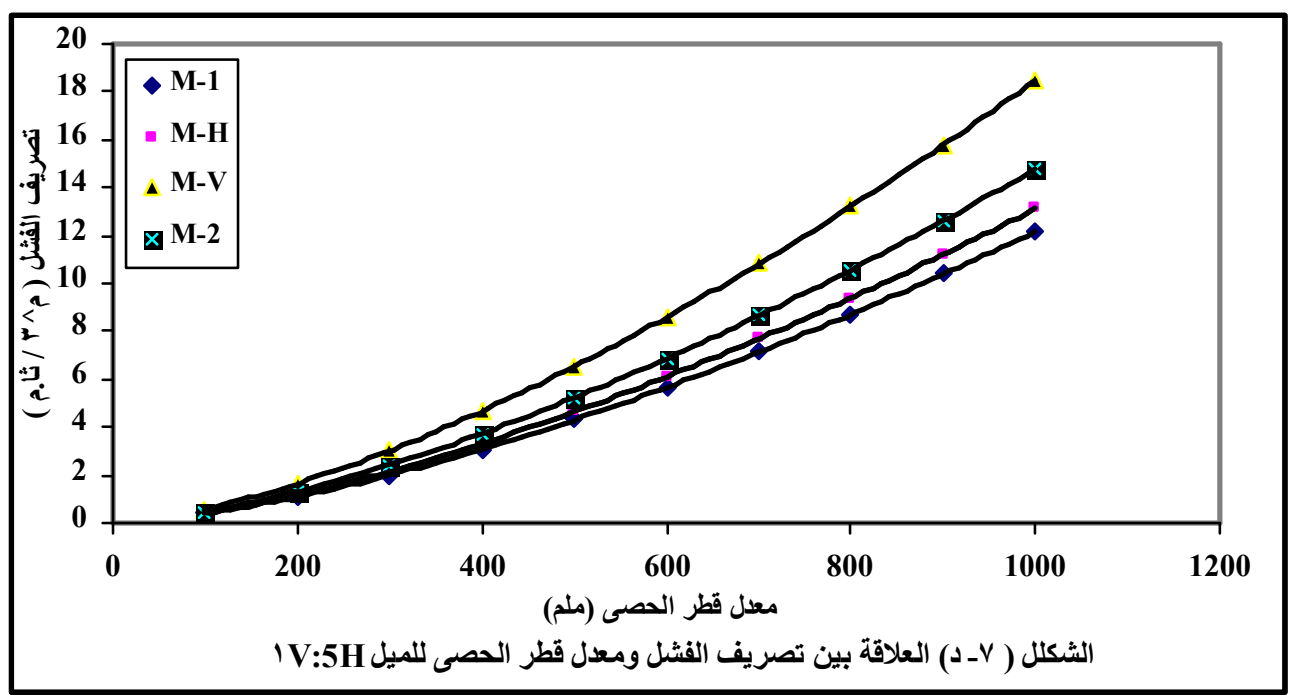



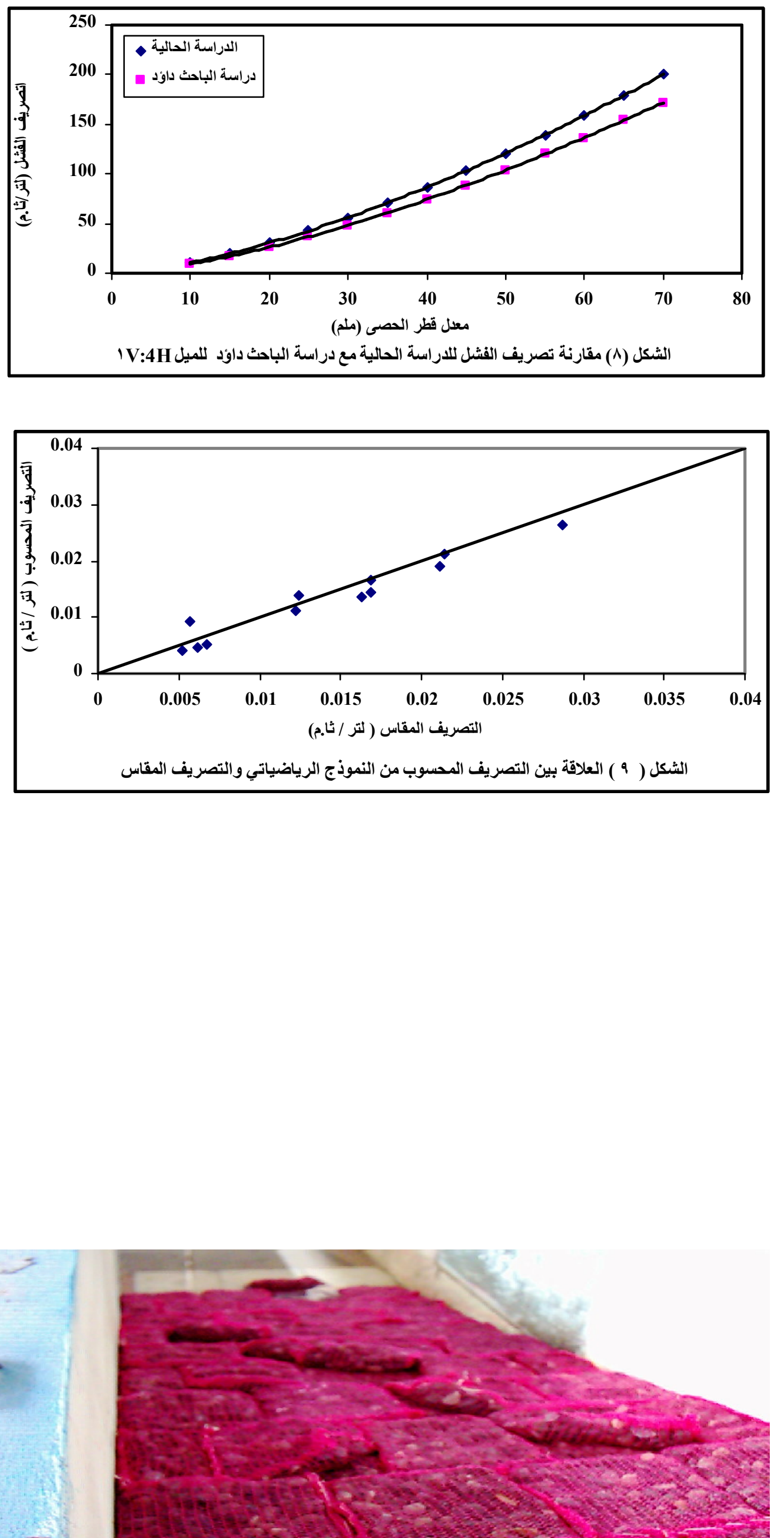
اللوحة (1) فثل الميل ( 1V:4H) للحالة (M-2) و الكتلة 1.22 كغم

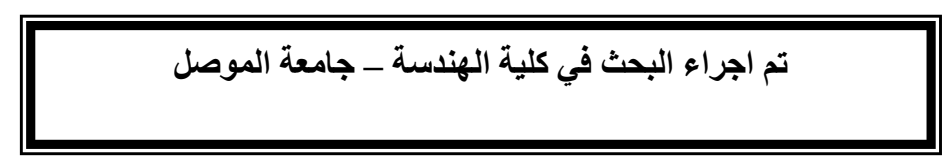

